Hershkovitz Montiaceae Phylogeny \& Phylogeography

\title{
Perspectives from Montiaceae (Portulacineae) Evolution. I. Phylogeny and Phylogeography
}

\author{
Mark A. Hershkovitz ${ }^{1}$
}

${ }^{1}$ Santiago, Chile

cistanthe@gmail.com

\begin{abstract}
Montiaceae comprise a clade of at least 270 species plus about 20 accepted subspecific taxa, primarily of western America and Australia. The present paper is the first of a two-part work that seeks to evaluate evolutionary theory via metadata analysis of Montiaceae. In particular, it uses metadata analysis to evaluate the theory in theory-laden methods that have been applied in evolutionary analyses of Montiaceae. This part focuses on phylogeny and phylogeography. The second part focuses on phenotypic and ecological diversification. An emergent theme in this paper is the degree to which historical idiosyncrasy during Montiaceae evolution misleads quantitative methods of evolutionary reconstruction and phylogeographic interpretation. This suggests that idiosyncraticity itself is a fundamental property of evolution. The second part of this work elaborates this notion as the Principle of Evolutionary Idiosyncraticity. The present part describes idiosyncraticity in molecular phylogenetic and phylogeographic data and uses this notion to refine ideas on Montiaceae evolution. Phylogenetic metadata conflicts and conflicting phylogeographic interpretations are discussed. I conclude that, owing to PEI, quantitative methods of evolutionary analysis cannot be globally accurate, though they are useful heuristically. In contrast, classical narrative analysis is robust in the face of PEI.
\end{abstract}

KEY WORDS: Montiaceae, phylogeny, phylogeography, long-distance dispersal, idiosyncrasy, Principal of Evolutionary Idiosyncraticity.

\section{BACKGROUND}

Montiaceae (Portulacineae) comprise a clade of ca. 270 largely herbaceous (rarely suffruticose or pachycaul) species and ca. 20 additional subspecific taxa distributed mainly in western America, with additional endemism in eastern North America, Siberia, Australia, New Zealand, and the Kerguelen Islands. A current taxonomy of the family, applied in this work, is elaborated in [1]. Over the past three decades, Montiaceae have been subjected to several evolutionary analyses. These analyses provide the 
metadata in the present synthesis of "whole taxon" evolution. This text is the first of a two-part work that critically reviews of aspects of evolutionary theory and analysis as viewed from the perspective of metadata analyses of Montiaceae. This part focuses on phylogeny and historical biogeography. The second part [2] focuses on the relation between phenotypic, genomic, and ecological evolution.

A recurring theme in this work is the extent to which conventional epistemological approaches to Montiaceae evolutionary analyses have failed to predict empirically observed exceptions to their explicit or implicit evolutionary rules. The epistemological approaches have optimized evolution according to one or another monotonic function or criterion, either a likelihood function of a presumed evolutionary model or a parsimony criterion. In individual studies, observations not conforming to the assumptions of the model or criterion appear as data "idiosyncrasies." In evolutionary analytical practice, these idiosyncrasies tend to be variously overlooked, observed but disregarded, or explained ad hoc. But what is impressive is that idiosyncratic data behavior seems to emerge in all evolutionary analyses. This suggests the possibility that idiosyncrasy itself is a pattern in evolution, and this is the thesis defended here.

The present work and [2] are entitled "Perspectives from..." rather than "Perspectives on..." for a reason. Indeed, they provide perspectives "on," but the effort is motivated more by what metadata analysis of Montiaceae indicates about the evolutionary process in general. Rather than impose theoretical and methodological dogma on the data, I attempt to let the data explain themselves. The main reason for idiosyncratic data behavior (aside from data error) owes not per se to model or criterion imprecision or misspecification, but to the idiosyncraticity of evolution itself. The second part of this work [2] describes this as the Principle of Evolutionary Idiosyncraticity (PEI), and argues that PEI applies not only to data that do not conform to the presumed optimization model or criterion, but to those that do, as well. The latter simply are equivalent to localized "replicate" data that happen to predominate in many data sets, sometimes because of subliminal bias to select such data sets for analysis. These create the (pseudo)patterns that seem to implicate commonality of process (e.g., cladogenesis). Presumed commonality of process, in turn, forms the basis of evolutionary analytical models or criteria. The model or criterion then straightjackets evolutionary analysis and interpretation, i.e., what seems to have happened most of the time should happen all of the time. The second part of this work [2] explains PEI in terms of chaos theory, stochasticity, and non-Darwinian evolutionary theory. And it demonstrates that PEI manifests in other evolutionary analyses, as well, including in vivo evolutionary experiments.

This part begins with an evaluation of phylogenetic analyses of Montiaceae. Here first emerges the dilemma consequent to application of linear models to analyze idiosyncratic processes. Conventional methods of phylogenetic analysis presume a linear process and, accordingly, intrinsically impose this order on data analyzed and occlude evidence for evolutionary idiosyncraticity. The present biogeographic 
Hershkovitz Montiaceae Phylogeny and Phylogeography

1

analysis of Montiaceae then emphasizes the idiosyncratic origin of biogeographic "pseudopattern." Superficially, Montiaceae distributions appear to conform with an origin prior to the Pangaean or Gondwanan breakup. But phylogenetic dating estimates indicate that transcontinental disjunctions reflect numerous more recent long distance dispersal (LDD) events. The significance of these results in the context of phylogeographic theory is elaborated.

\section{PERSPECTIVES FROM CURRENT EVIDENCE FOR MONTIACEAE PHYLOGENY}

This discussion does not cover each resolved and unresolved node of Montiaceae phylogeny. It emphasizes aspects of the phylogeny that reemerge in subsequent discussion of phenotypic, genotypic, and phylogeographic evolution. But I also discuss here aspects of phylogeny per se as they manifest idiosyncrasy in phylogeny and evolution of the gene sequences used to reconstruct it. For example, a reemerging pattern in Montiaceae molecular phylogeny is clusters of shorter branches separated by fewer longer ones. The significance of this pattern will be discussed in terms of assumptions of phylogenetic reconstructive methods and implications for interpretation of genotypic and phenotypic evolution. I also highlight idiosyncratic taxon origins, i.e., the significance of the origin of taxa whose phenotypes depart markedly from those of their broader clade. The significance of apparent conflicts among genomic data sets also is discussed.

\section{Montiaceae circumscription, sister-group, and backbone phylogeny}

Cladistic morphological analyses of Carolin [3, 4] and Hershkovitz [5, 6] radically modified classical taxonomy of Portulacaceae [7, 8]. Especially Hershkovitz [6] emphasized evidence for a clade comprising the taxa diversified mainly in far-western America and Australia ("western American Portulacaceae"). Molecular phylogenetic analyses $[9,10]$ confirmed the major conclusions of the morphological analyses and identified a clade comprising western American Portulacaceae plus the genus Phemeranthus. The latter conventionally had been classified in the genus Talinum. Applequist et al. [11] and Wagstaff \& Hennion [12] later demonstrated that Hectorelleae are nested in this clade. Nyffeler \& Eggli [13] later classified this clade as Montiaceae. This classification is currently broadly accepted [14]. The present work and [2] follow taxonomy slightly modified from [1]. Full authored names of subgeneric taxa are provided at the end of this text.

Analyses based on multiple markers [15-18] strongly support a sister relation between Montiaceae and a clade comprising all other taxa of Portulacineae. The latter clade comprises seven 
Hershkovitz Montiaceae Phylogeny and Phylogeography

families, three of which, like Montiaceae, are segregates of classical Portulacaceae [14]. Portulacineae is sister to the current circumscription of Molluginaceae [15-18].

Preliminary DNA analyses of Montiaceae $[9,10,19]$ revealed high divergence among genericlevel clades but low divergence within several of them. Interspecific divergence/resolution was minimal within subclades Cistanthe, Calyptridium, Calandrinia, and Montiopsis. Similar minimal resolution/divergence was reported for a large Phemeranthus subclade [20]. At the other extreme, fewlocus divergence/resolution is greatest among Montia and many annual Claytonia species [21]. This result seemed peculiar, given that Montieae are the most recently diverged clade of Montiaceae. However, there is little divergence/resolution between and among the caudiciform and tuberous Claytonia species, which had been classified in different sections [21, 22]. A phylogenomic analysis of 297 loci yielded a relatively highly resolved tree of 77 samples of Rumicastrum comprising all 48 described species plus several putative ones [17]. This may indicate that phylogenomic approaches will yield comparable resolution in as yet poorly resolved nodes.

Ogburn \& Edwards [16] reanalyzed Montiaceae phylogeny with additional DNA sequence markers and more recently developed implementations of both maximum likelihood (ML) and Bayesian phylogenetic estimation (BE). They analyzed two data sets: an 89-terminal three-marker set (plastome trn $\mathrm{K}-m a t \mathrm{~K}$ and $n d h \mathrm{~F}$; nucleosome $p h y \mathrm{C}$ ); and a 142-terminal five-marker set (the preceding plus plastome $y c f 3$-trnS spacer and nucleosome rDNA-ITS).The latter dataset included earlier data of [19]. These markers are more variable than the others at the interspecific level. Not all sequences were available for all samples.

Smith et al. [18] included 207 Montiaceae samples in a nearly 5000-taxon phylogenetic analysis of Caryophyllales. They incorporated data from plastome $m a t \mathrm{~K}, n d h \mathrm{~F}, r b c \mathrm{~L}$ genes and $t r n \mathrm{H}-p s b \mathrm{~A}$ and $\operatorname{trn} \mathrm{L}-\operatorname{trn} \mathrm{F}$ spacers, and nucleosome rDNA-ITS and $p h y \mathrm{C}$. Again, not all markers were available for all taxa, though this hardly matters for the more highly conserved ones. Smith et al. [18] used an analytical protocol optimized for large datasets [23]. Their protocol uses ML trees derived from bootstrapped data to simultaneously optimize the full data ML tree and estimate edge support via an approximate likelihood ratio test. Under ideal circumstances, these edge support values approximate conventional bootstrap values [23], but these conditions are not met in the case of Montiaceae phylogeny (see below).

Hancock et al. [17] included samples of most major Montiaceae clades in their phylogenomic analysis of the thoroughly sampled Rumicastrum. They analyzed four datasets extracted from a total 297 loci comprising more than $3 \times 10^{5}$ DNA base pairs. The datasets differed according to a criterion of higher/lower proportions of loci/sites shared among higher/lower proportions of sampled individuals. Each dataset was analyzed using two methods, one as in [18] and the other a coalescence-based approach. Thus, the analysis includes a total of 12 data/method combinations. They also performed a Bayesian 
analysis of phylogenetic concordance among loci, which estimates the proportion of total loci that support conflicting topologies.

The present discussion will emphasize especially the results of Ogburn \& Edwards [16] and, where conflicting, Hancock et al. [17]. The Smith et al. analysis [18] will not be emphasized, because it was optimized for sampling of all Caryophyllales and not, specifically, Montiaceae, and because of possible methodological artifacts. Hancock et al. [17] might share these artifacts, but their principal results agreed using three very different methods. However, the coalescent and Bayesian concordance methods they applied are relatively new, as are phylogenomic sampling methods generally. Unfortunately, the data and methods themselves become too complex to scrutinize by eye. Current methodological emphasis is on analytical speed and data quantity and the statistical preponderance of recovered clades, with the hope that preponderance alone obviates the need for detailed scrutiny.

Using the taxonomy in [1], and with caveats discussed below, current molecular phylogenetic evidence suggests the following [16: Fig. 2; 17: Figs. 3-4]:

1. Phemeranthus as the outgroup of the remainder of Montiaceae. This accords with morphological and phylogeographic evidence, as will be discussed in a later section. Hershkovitz [1] classified Phemeranthus and Schreiteria in Phemerantheae.

2. Divergence/diversification of Cistantheae, a principally Chilean (semi-)arid region lineage that includes: (a) Cistanthe; (b) Montiopsis; and (c) Calyptridinae, comprising Lenzia, Calyptridium, and Philippiamra.

3. Monophyly of Montioideae, a morphologically/ecologically more diverse and geographically more broadly distributed lineage comprising the remaining Montiaceae.

4. Calandrinia and Rumicastrum as the successive outgroups of remaining Montioideae. One of the 12 data/method combinations in [17] yielded maximal support for a conflicting topology, in which Calandrinia is sister to Cistantheae.

5. Hectorelleae as sister to the preceding. Support for this relation degenerates markedly in the five- compared to the three-marker data [17], but no Hectorelleae data were available for ITS of $y c f 3-t r n \mathrm{~S}$. This suggests that the inclusion in the latter of more rapidly-evolving markers introduced not conflict, but noise that perturbed the BPs and PPs

6. Divergence/diversification of Montieae, a principally western North American lineage including Lewisiopsis, Lewisia, Claytonia, and Montia.

7. The uncontroversial sister relation of Claytonia and Montia, often classified as Montieae, but here classified as Montiinae.

All of the preceding are recovered in all but one of the 12 phylogenomic analyses [9], but there is significant discrepancy in support for these in the three-marker versus five-marker data sets of [16]. 
Hershkovitz Montiaceae Phylogeny and Phylogeography

Backbone branches in the three-marker set are recovered mostly with very high to maximum ML bootstrap proportions (BP) and BE posterior probability (PP) values. These backbone branches are unresolved in [19]. The five-marker data set incorporates data from [19]. Oddly enough, support for most of the backbone degenerates. BP values fall, in several cases to below $70 \%$ and, in some, to below $50 \%$. Likewise, PP values decline nontrivially, some to below 50\%. The interpretation and/or reliability of both of BPs and PPs in the context of phylogenetic analysis have been a contentious theme (see below). In any case, increasing data size ought to maintain or increase BP/PP values. The observed decreases, even slight ones in the case of PPs, suggests that something is "wrong."

Ogburn \& Edwards [16] acknowledged, but did not explain, discrepancies between their two data sets. It resembles dataset conflict, where the data reflect different histories, as can occur with hybridization. The possibility might be explored by analyzing the three plastome and two nucleosome markers separately (see also below). Another possible source of discrepancy is methodological. Hershkovitz [19] analyzed the ITS data using maximum parsimony (MP), especially in order to accommodate information from coded indels. Ogburn \& Edwards [16] used an ML protocol, which does not accommodate indel data. But these differences do not explain the discrepancy in Ogburn \& Edwards' [16] two analyses.

It should be reiterated that $\mathrm{BP}$ and $\mathrm{PP}$ values estimate different aspects of tree reliability. Interpretation of BPs in phylogenetics [24] is not straightforward [25-31]. Theoretically, they are not probabilities, but confidence intervals (but see [29]). However, BPs generally are considered to be conservative predictors of tree reliability. Of course, the bootstrap can be no more consistent statistically than the tree reconstruction procedure it applies. While PPs are considered to represent (estimates of) conventional probabilities of clades, they are known to be severely overestimated in certain circumstances [26, 30-32]. Nonetheless, coincidence of high BP and PP values has been considered to be a reassuring measure of tree reliability [27] - unless, of course, both happen to be coincidentally misleading. The latter possibility emerges in the case where the evolutionary process violates the assumptions of the analytical model or criterion. This can cause BP and PP values to behave inconsistently, i.e., indicate high support for the wrong result. This model/criterion misspecification may be global across all the data, but, as discussed below, more likely it is local, yielding inconsistency in part of a phylogenetic tree but not all of it.

It must be stressed also that the mere specification of estimation method (e.g., MP, ML, BE, and alignment methods), credibility measure and values (e.g., BP, PP), and computer programs are not sufficiently informative to judge the reliability of published phylogenetic trees and statistics. Methods are distinct theoretically and their implementations are distinct in practice. All methods make assumptions about the analyzed data, and implementations generally permit considerable user manipulation. BE 
Hershkovitz Montiaceae Phylogeny and Phylogeography

1 methods are the most variable theoretically/methodologically and the most contentious philosophically.

2 To paraphrase Dragicevic [33], computer methods and results should be used to augment-not substitute

3 for-human cognition.

The discrepancy between three-maker and five-marker results in [16] might owe to idiosyncrasies in molecular evolution that violate the assumptions of the statistical phylogenetic analysis methods. However, all of the assumption violations are parametric components of one single assumption: that evolution is a linear process. As elaborated especially in the second part of this work [2], this assumption is questionable and probably wrong. Idiosyncraticity emerges a property of a nonlinear stochasticallyperturbed chaos-like process. It yields known or plausible phenomena not predicted by standard statistical analytical methods. Standard methods correct only for certain statistically detectable patterns of substitution bias evident in comparative DNA sequence analysis (e.g., [34]). There are caveats, often ignored in method application (see, e.g., [27]). A few caveats relevant to the present problem include:

1. Commonly implemented methods do not correct for all known sources of substitution bias (e.g., consequent to DNA/RNA secondary structure), nor other idiosyncratic features of DNA sequence evolution not detectable statistically and/or not corrected in existing computational methods. Conventional methods apply a general time-reversible base substitution model with corrections for base compositional bias and among-site rate-heterogeneity [34].

2. Statistical precision in those substitution biases methodologically estimated is contingent upon maximal DNA sequence sampling and maximal DNA divergence among sequences. This sampling-divergence breadth, in turn, increases the likelihood of occurrence of localized idiosyncratic and/or uncorrected substitution biases. But implemented methods estimate and apply uniform (stationary) substitution models over the entire phylogeny, thus ignoring local variation. Nonstationary models exist, but they present both technical and theoretical problems. Most importantly, they converge on branch-specificity of models, which is the same as absolute idiosyncrasy of molecular evolution or, effectively, no statistical model at all [34].

3. ML phylogenetic analysis ignores variance in those substitution biases estimated. BE methods permit but do not obligate incorporation of such variance in PP calculation (but see above).

4. Even if substitution bias were a linear and uniform process, accurate phylogenetic estimation is compromised by inadequate phylogenetic signal along internal branches and algorithmic determination bias [23]. 
Hershkovitz Montiaceae Phylogeny and Phylogeography

5. Statistical DNA phylogenetic reconstruction restricts analysis to (putatively) aligned substitutions and ignores informative indel characters. The latter can be numerous especially in intron and ribosomal DNA sequences.

6. Under the best of possible circumstances relating to the preceding, accuracy of phylogenetic estimation remains compromised by discrepancies between gene and organism phylogeny (hybridization and lineage sorting; see below), as well as certain extreme branch lengthassociated artifacts.

The articulation above is not gratuitous (nor exhaustive). Studies of Portulacineae and their DNA sequences [9, 10, 19; Hershkovitz, unpublished data] yielded evidence of such violations of methodological assumptions. Implemented methods may well be robust to most assumption violations and/or in most of the resultant phylogenetic resolution. But no methodology exists to detect localized failures. Conflicts emerging from different analyses provide a clue. Possible causes of this conflict are articulated below.

Hershkovitz \& Zimmer [9] illustrated base compositional bias in ITS across Portulacineae. GC content of variable sites varied about two-fold across the order, highest among "anacampseroid" taxa (Anacampserotaceae; [14]) and lowest in the genus Claytonia. Among Montiaceae, the difference is about $50 \%$, the highest $\mathrm{GC}$ values among Cistantheae, with a phylogenetic trend in Montioideae towards the minimal values in Claytonia. Consequently, the base substitution kinetics among Cistanthe and Montioideae cannot be the same. Base compositional bias was not examined in plastomic ycf3-trnS data [19], although, like plastomic sequences in general, these have $<50 \% \mathrm{GC}$ content.

Considerable overall substitution rate heterogeneity also is evident among Portulacineae, including among Montiaceae (see figures in $[9,10,19])$. Coincident with the change in base composition in Montioideae, their substitution rate increases. Based on phylogram branch lengths, the rate in Claytonia appears to be up to five times faster than among Cistantheae. Interestingly, this increase is evident in both the ITS and plastome data, though I have not analyzed base compositional nonstationarity in the latter. This contrast is especially evident in Lewisiopsis: its divergences from the root of ITS and plastome trees, as well as phylogenomic trees [17], are far less than for closely related taxa. This lower sequence divergence coincides with lower morphological divergence of Lewisiopsis: its morphology resembles that of Cistanthe sect. Cistanthe species [5, 6, 35, 36]. I explain this further below in the context of a hybrid origin of Lewisiopsis. Overall substitution rate heterogeneity per se does not violate assumptions of substitution bias models. Its effect on phylogenetic analysis may emerge as a consequence of localized tree branch length asymmetry.

Another pattern evident from published phylograms especially of Montiaceae [19: Figs. 1, 2] is pervasive branch length asymmetry. In particular, there appear to be excess high and low divergences 
relative to medium divergences. Internal branches along the backbone are short and unresolved, the emerging branches longer, and interspecific level branches again short and unresolved. While sequences of genera cluster, interspecific sequence divergence is extremely low, especially in Cistanthe, Calyptridium, Montiopsis, Calandrinia, and (unpublished data) Lewisia. These asymmetries have several possible causes, all of which violate analytical methodological assumptions. The pattern renders artifacts, especially using the method applied by [18; cf. 23].

The asymmetries might be explained as molecular punctuated equilibria. In particular, especially the ITS sequences apparently are functionally constrained (e.g. to maintain secondary structure and/or genomic-level processes) such that particular sequence "morphologies" are evolutionarily more stable than others. Evolution from one to another molecular morphology may involve a combination of substitutions and insertions/deletions that fix rapidly in the genome. Thus, ITS sequences possess phylogenetic signatures conserved hierarchically at remarkably deep phylogenetic levels [37-39]. But the evolutionary steps between forms are not so conserved, yielding bushy phylogenetic trees.

The preceding suggests that ITS violates the single most important assumption of ML DNA phylogenetic analysis: that the DNA sequence evolution process is uniform across the phylogeny (see [23]. Thus, by increasing marker number, [16] may have added "noise" to "signal." This would predict reductions in both the ML BP and BE PP values.

The analysis of [19] avoided this problem by employing only MP and incorporating discrete multi-site indel data as characters. This avoided two problems: spurious alignment of length-variable noncoding ITS and $y c f 3$-trnS and sequence regions, and spurious imposition of locally erroneous substitution models owing to nonstationarity. Relations along the backbone were "unresolved" as opposed to spurious. This point is critical, because the virtue of global ML model s [40] becomes their weakness in the case of nonstationarity. Nonstationarity might yield artifacts with MP, but MP formally is agnostic towards substitution probability, whether stationary or not. At the same time, incorporation of indel data contributed significantly to phylogenetic resolution at lower divergences. Here, divergence often owed primarily or completely to length variation and rather than substitution.

Another explanation of the three- and five-marker tree conflict implicates lack of concordance between gene and taxon trees. Hershkovitz [19], I emphasized that apparent rapid bursts of molecular divergence coincided with those of morphological divergence, and suggested that the pattern might owe to both contemporary and ancient factors that might decouple the gene and taxon trees, hybridization in particular. In the case of the backbone, this may reflect rapid diversification within the ancient species dimension. In that dimension, hybridization and lineage sorting would be expected. This also would explain dataset-specific conflict. Whole-genome phylogenetic analyses are beginning to reveal heretofore unappreciated degrees of hybridization and/or lineage sorting during the course of plant phylogeny, not 
Hershkovitz Montiaceae Phylogeny and Phylogeography

only among recently evolved species, but at what are now deeper cladogenetic levels (e.g., [41]. These results impact not only interpretation of genealogy, but also phenotypic evolution, as elaborated more below and in [2].

Nonetheless, until the conflict between the three- and five-marker trees can be satisfactorily explained, choice between them is arbitrary and must be regarded as provisional. Ogburn \& Edwards [16] used the statistically less well-supported five-marker topology for their subsequent evolutionary analysis of phenotype. The latter did, however, include protocols to account for a degree of phylogenetic uncertainty. One would hope that any accommodation of phylogenetic uncertainty helps to avoid spurious conclusions. However, while genotypes and phenotypes indeed are consequent to phylogeny, phylogenetic trees and analytical derivations thereof are not. These are consequent to reconstructive and interpretive methods and data accuracy. As emphasized repeatedly here and in the final section of [2], quantitative methods are valuable heuristically, but they unavoidably canalize the truth that they seek to discover.

\section{Phylogeny of Cistantheae}

The refutation in [19] of the earlier proposed generic circumscription of Cistanthe [5, 6] was confirmed in [16]. In particular, [19] demonstrated that Lenzia is the sister taxon of a clade comprising Calyptridium and Philippiamra (see [1] ). Hershkovitz [5, 6] classified these genera in Cistanthe. This clade, denominated the "Philippiamra lineage" in [16\} is classified in [1] as Calyptridinae. But the increased resolution of intergeneric relations in [16] revealed something new: a clade comprising Calyptridinae and Cistanthe (s. str.) with Montiopsis nested therein. This result is strongly supported in all of the phylogenomic analyses in [17]. All molecular analyses [9, 10, 19, 16, 18; but see below] have refuted the inclusion of Lewisiopsis in Cistanthe $[5,6,36]$. However, phenetic similarity of both DNA and morphology between Lewisiopsis and Cistanthe remains tantalizing, suggesting their similarity bases on ancient homology rather than convergence (see also below).

The relations of Lenzia emergent in [19] were surprising. Lenzia chamaepitys is a peculiar plant that bears no resemblance to other Calyptridinae. The plant resembles a small scaly cone, about $2 \mathrm{~cm}$ high, the densely packed awl-like leaves markedly scarious and broadly membranous along both margins, with the narrow mesophyll cladodromously vascularized. Reportedly the plants bear solitary, axillary flowers, but I have never seen these. The plants evidently are clonal, connected by delicate rhizomes. Hershkovitz [19] mentions that, if anything in nearby Montiaceae, Lenzia most closely resembles acaulescent perennial alpine species of Calandrinia and perhaps also Montiopsis (subg. Dianthoideae) cistiflora. Ecologically, Lenzia is distinctive in being restricted to the driest sector of the Andean alpine 
Hershkovitz

Montiaceae Phylogeny and Phylogeography

zone, where the "arid diagonal" crosses the cordillera. Here, the high cordillera generally is at the limits of the range of both the (southern hemisphere) summer Atlantic moisture arriving from the north and east and the winter Pacific moisture arriving from the south and west.

Significantly, the cladograms in $[16,17]$ permit deeper-level homology of the morphological traits [5, 6, 35] shared by Calyptridium and Philippiamra with Cistanthe, these being lost in Lenzia and Montiopsis. These include: (i) succulence; (ii) oblanceolate leaves often differentiated into a more rhombic apical portion and broad linear basal portion; (iii) laminate (ribbon-like) leaf vein anatomy; (iv) an "indeterminate" primary leaf vein; (v) weakly but definitely brochidodromous secondary leaf veins; (vi) brachyparacytic stomata; (vii) cymose inflorescences in the form of a cincinuss; and (viii) markedly unequal inflorescence bracts. This trait complex characterizes no other Montiaceae. Calyptridium and Philippiamra species differ from Cistanthe mainly in having reductions in floral part number, but the genera intergrade [5,6]. Thus, not anticipating the idiosyncratic evolution of Lenzia and evidently Montiopsis, the earlier morphological circumscription of Cistanthe [5, 6 ] seemed reasonable. In this sense, the analysis in [16] corroborates the morphological analytical conclusions. However, [16] emphasizes only paraphyly of Cistanthe sensu $[5,6]$ and does not discuss morphological phylogenetic evidence. In Chile, plants of Philippiamra and Cistanthe also intergrade ecologically. The former are decidedly more xerophytic than the latter, but in many arid locations, species of both groups grow sideby-side. This was circumstantial evidence that the latter derived from among the former.

The inclusion of Montiopsis in Cistantheae deserves comment, because the morphology can be described as idiosyncratic. Species of Montiopsis bear no obvious synapomorphy with other Cistantheae. They are distinctive among all Montiaceae (and Portulacineae) in bearing multiseriate-multicellular trichomes, these sometimes also glandular [3, 6, 42-44]. Otherwise, only short unicellular foliar trichomes/papillae occur among Portulacineae (although some clades are characterized by axil-specific trichomes $[3,6])$.

Hershkovitz [6] described the Montiopsis inflorescence as botryoid or a bostryx are thyrsoid (but solitary in M. cistiflora), and the sepals are irregularly dentate-erose. Among Portulacineae, the inflorescence is unique and the sepal trait traits occur only among certain species of Lewisia. Montiopsis comprises two monophyletic subgenera, M. subg. Montiopsis and M. subg. Dianthoideae, these comprising ca. 17 and four species, respectively [44]. Subgenus Montiopsis is more diverse and more specialized: perennials (all alpine) and annuals (sea-level to alpine), distributed from southern Bolivia to southern Chile and across broad temperature/precipitation regimes. In addition to the trichome forms shared with $M$. subg. Dianthoideae, all species bear unique multiseriate-unicelluar trichomes formed by fusion of long epidermal hair cells. All species have pantoporate pollen. Species of $M$. subg. 
Hershkovitz Montiaceae Phylogeny and Phylogeography

Dianthoideae, by contrast, are all alpine perennials restricted to the central Chilean Andes and all have tricolpate pollen.

With some caveats, the inclusion of Montiopsis in Cistantheae seems well-supported [16, 17]. However, the five-marker cladogram in [16] shows reduced support for Cistantheae monophyly relative to the three-marker cladogram. The BP and PP reduce from $100 \%$ to $69 \%$ and 1.0 to 0.99 , respectively. While these reductions are not as severe as those observed at other nodes, they are not trivial. Edge support for Cistantheae in [18] is $<50 \%$; for Cistanthe + Montiopsis is $62 \%$; and for Calyptridinae is $64 \%$. All of the analyses in [17] yield maximal support for Cistantheae (though Lenzia was not sampled). However, the concordance analysis in [17] manifests nontrivial support for monophyly of Cistanthe plus Calyptridinae. In all analyses, Montiopsis "sticks out" of Cistantheae, i.e., it is subtended by a long branch and the terminals extend further than the terminals of other Cistantheae.

These morphological and molecular data indicate that something has "gone down" during the origin and evolution of Cistantheae. Although there is a small level of conflict regarding the placement of Montiopsis within Cistantheae, the support seems to outweigh this. The conflict may be an artifact of the long branch subtending the genus. The result is that Cistantheae includes two genera that are phenotypically very similar in both vegetative and reproductive morphology, differing only in the degree of congestion of the inflorescence and, correspondingly, the size of the flowers. And from this emerge two genera, Lenzia and Montiopsis, which are morphologically divergent from all other Montiaceae. Is this unusual? My thesis is that idiosyncraticity is the norm. Further scrutiny of morphological and genomic data will help explain mechanically the origins of the peculiar taxa. But the observation itself has broader implications for evolutionary analysis. It is evidence against the monotony of the evolutionary process that evolutionary analytical methods presume and, in fact, impose.

\section{Phylogeny and taxonomy within Calyptridinae}

Hershkovitz [5,6] concluded that the classically conceived genus Calyptridium (including Spraguea; [45]) pertained to a clade comprising also Reiche's [46, 47] Calandrinia section Amarantoideae and the genus Philippiamra. I refer below to this group as the "CAP" clade. Carolin's cladogram [3], in contrast, split the CAP clade, with Cistanthe s. str. arising in between the Calyptridium and Philippiamra. Still, both cladograms agreed on monophyly of these taxa together. Hershkovitz thus classified classical Calyptridium, Philippiamra, and Calandrinia sect. Amarantoideae as sections within the genus Cistanthe [5, 6, 48, 49; cf. 3, 4]. Molecular analyses in [16] corroborate [19] with respect to phylogeny within Calyptridinae. 
Hershkovitz Montiaceae Phylogeny and Phylogeography

Current DNA sequence evidence $[19,50]$ demarcates two speciose clades in Calyptridinae: (1) Calyptridium sensu Hinton [45]; and (2) Philippiamra. Support for Philippiamra stems from the essentially identical DNA marker sequences of its species, regardless of floral/fruit morphology [19]. There are two morphologies: a Calandrinia-type, with five petals/stamens, three carpels, and multiseeded valvate capsules; and a Philippiamra-type, with reduced petal/stamen numbers, two carpels, and a one-seeded indehiscent fruit. Based on this floral/fruit morphology, [8] classified these taxa in different genera and in different tribes of Portulacaceae. Yet, their genotypes overlap, some samples of differing morphology sharing identical ribosomal and plastome sequences. From the DNA evidence, it is not clear that the Philippiamra-type morphology evolved only once, although a single origin followed by hybridization also is possible.

DNA evidence, morphology, and cytology mutually support monophyly of the bicarpellate species of Calyptridium (sensu Hinton [45]). Likewise the data support monophyly of $C$ sect. Spraguea $[16,19,50]$, but not so convincingly $C$. sect. Calyptridium. Species of $C$. sect. Spraguea (two perennial and one annual) share three synapomorphies: loss of the smaller of the two unequal inflorescence bracts; loss of laminar leaf venation; and leaves coriaceous rather than succulent $[5,35]$. The perennial condition is derived [2]. Species of $C$. sect. Calyptridium and $C$. sect. Thingia have bracts, leaf veins, and leaf texture the same as species of Philippiamra, especially P. calycina.

Low bootstrap support in [19] for the bicarpellate clade is an artifact of the short branch separating these species from the tricarpellate Calyptridium ambiguum. Thus, many bootstrap samples may have missed the supporting data and/or duplicated data that created spurious relations between $C$. ambiguum and particular bicarpellate Calyptridium species. The collective DNA evidence [16, 19, 50], phylogeography and morphology suggest but do not prove that $C$. ambiguum as sister to the remainder of Calyptridium.

Returning to taxonomy, an argument could be made for recognizing C. ambiguum as a distinct genus, which not only renders the remainder of Calyptridium more homogeneous, but also conserves traditional local taxonomic custom. Calyptridium ambiguum has Calandrinia-type floral/fruit morphology, for which reason [43] included it in Reiche's [46, 47] Calandrinia sect. Amarantoideae. It is the only species of Cistantheae with basket-forming three-dimensional leaf venation [35; not reported in $51]$.

At the same time, an argument can be made for classifying all species of this clade as Calyptridium: the consequent overall divergence/diversity is comparable to that in most other Montiaceae genera. Splitting into two genera is justified on the basis that each resultant genus has considerable species diversity in its respective hemisphere, and it maximally conserves prevalent taxonomy. Splitting Calyptridium further is no more and probably less justifiable than historical but currently rejected generic 
Hershkovitz

Montiaceae Phylogeny and Phylogeography

1

segregations within Lewisia and Montia. Still, in the event that segregation of C. ambiguum is preferred, a monotypic genus, Thingia, has been erected to accommodate it [1].

\section{Lewisiopsis - a living fossil?}

The phylogenetic relations of Lewisiopsis conflict strongly among the various analyses. A sister relation with Lewisia was supported by maximal PP and fairly high BP in both the three- and five-marker analyses of [16]. However, a sister relation with remaining Montieae received maximal support in all 12 analyses of [17]. But the latter authors did not note this discrepancy. The sister-relation to Lewisia received $84 \%$ support from MP analysis of $y c f 3-t r n S$ data in [19]. The optimal ITS MP tree indicated the sister relation to Montieae, but with $<50 \%$ BP. However, in the combined MP analysis, BP support for the Lewisia relation reduced to $56 \%$, indicating conflict between the nucleosome and plastome. This conflict seems to be corroborated by [16] and [17], as the former included mostly plastome data and the latter presumably overwhelmingly nucleosome data. Also, BP support for the Lewisiopsis/Lewisia sister relation in [16] declined from $96 \%$ in the three-marker dataset to $93 \%$ in the five-marker dataset. The latter added proportionally more nucleosome data. As BP maxima in the three-marker data likely were limited at low divergences by lack of informative sites, this difference is more significant than it appears.

The data suggest a new hypothesis regarding the evolution of Lewisiopsis. This monotype appears to be a "living fossil" of a hybrid between earliest and barely divergent ancestors of Lewisia and Montiinae. Further supporting this hypothesis is the high but irregular chromosome number in Lewisiopsis [52]. It is approximately octaploid relative to its diploid relatives. As noted above and in [5, $6,19,35,36]$, Lewisiopsis is pleisiomorphic in its morphology, plastome, and nucleosome. This pattern is confirmed by broader genomic sampling in [17]. The Lewisiopsis branch is markedly less divergent from the ancestor than all other Montieae and, indeed, all other Montioideae. As in previous analyses, the whole-genome divergence from the Montiaceae ancestor approximates that of Cistantheae.

Lewisiopsis might appear to be an exception to the dogma of the evolutionary consequences of hybridization and/or polyploidy. These processes are regarded widely as catalysts of cladistic diversification and genomic, phenotypic, and ecological diversification [41, 53]. In this case, the parental lineages, Montiinae and Lewisia diversified/evolved, but the hybrid offspring did not and its genomic evolution seems to have sequestered. One might conclude that the effect of hybridization/polyploidy has been evolutionarily inhibitory.

However, as elaborated in [2] in the context of PEI, the dogma is specious. Hybridization/polyploidization are ubiquitous processes during the course of plant evolution. Plant domestication/selection demonstrates that indeed these processes are valuable sources of myriad novel 
Hershkovitz Montiaceae Phylogeny and Phylogeography

forms - but probably more often failed crosses and uninteresting/undesirable forms relegated to the mulch heap. Nature is less forgiving and its mulch heap much bigger. Hybrids/polyploids are afforded no protected space or special care in Nature's nursery, and likely overwhelmingly die. The dogma also reflects determination bias. Systematists naturally tend to pursue studies of more diversified clades. Hybridization/polyploidy are ubiquitous, frequent, and, effectively, irreversible processes running in parallel to cladistic diversification and phenotypic and ecological evolution. It is to be expected that all taxa will accumulate hybridization/polyploidy footprints in their pedigree, those that subsequently radiate and those, like Lewisiopsis, that do not. These observations in no way negate described patterns of hybridization/polyploidy-associated radiations, nor developmental genetic evidence demonstrating associations between hybrid/duplicated genes and novel phenotypes. Rather, it demonstrates that hybridization/polyploidy are neither necessary nor sufficient for such phenomena to occur.

Nonetheless, the evidence suggests that Lewisiopsis may provide critical evidence for the interpretation of Montiaceae phenotypic evolution. While it is risky to interpret ancestral phenotypes in terms of modern ones (e.g., [54]), the coincidence of both phenotypic and genomic pleisiomorphy in Lewisiopsis suggests that the former indeed may be relictual and shared with certain Cistantheae. Yet, Lewisiopsis diverged three nodes and as much as $10 \times 10^{6}$ years later than Cistantheae [17: S18; cf. 16: Fig.2]. Thus, genomic comparison might reveal that Lewisiopsis and Cistanthe share a developmental bauplan from which phenotypes of other Montiaceae have diverged.

\section{Other significant nodes}

Additional nodes apparently resolved in Montiaceae have significance in terms of phenotypic evolution, especially with respect to life history and life form. This theme is emphasized in [2].

1. All cited DNA analyses demonstrate monophyly of both the perennial and annual clades of Calandrinia, which is not mutually supported by independent phenotypic traits [6, 42]. Hershkovitz [6] suggested that the perennial group was paraphyletic with respect to the annual.

2. Monophyly of the perennial Montiopsis subg. Dianthoideae, which lack a phenotypic synapomorphy [6].

3. Monophyly of Cistanthe sections Cistanthe and Rosulatae, each including annual and perennial species.

4. Despite poor overall resolution, monophyly of two subclades within Cistanthe sect. Rosulatae, each of which is polymorphic for life history. These subclades are recognized as subsections [1]. 
Hershkovitz Montiaceae Phylogeny and Phylogeography

5. Somewhat ambiguous support for monophyly of two principal groups of Lewisia, one comprising the "evergreen" species (Lewisia sect. Cotyledon [52, 55]). Leaves of these species are coriaceous and persist year to year. Resolution is poor among remaining species of the other subclade, which are morphologically diverse but share ephemerality of their leaves.

6. Monophyly of two subclades of Phemeranthus, one comprising the caulescent species, the other the acaulescent [20].

7. Monophyly of three Claytonia sections differing in life form/history: annual, rhizomatous perennial, and caudiciform taproot or tuberous [21, 22 ]. Again, this seems to rule out paraphyly, rendering less certain evolutionary polarities.

Although it may seem trivial to point out, monophyly described above (and in general) refers to existing evidence supporting monophyly of extant clade members. This does not implicate necessarily that the phenotypic differences between the clades originated in a single common ancestor or ancestral species that split into two. Gene trees, species trees, and phenotypic trait trees are presumed to substantially overlay, but they are not the same. Phenotypic synapomorphies can originate before or after molecular marker synapomorphies, and can originate also via lateral transfer. Whole genome analyses (e.g., $[22,41]$ ) just now are scratching the surface of the complexity underlying phylogenies artificially simplified by analysis of few genetic markers. Thus, the sense of monophyly applied in this work and in $[1,2]$ is simplistic and may be naïve.

\section{Summary: phylogenetic conceptualization of Montiaceae}

Beginning with Carolin's [3, cf. 56] seminal work, understanding of evolutionary relations among Portulacineae and Montiaceae transformed radically from ideas persistent and pervasive up to the end of the $20^{\text {th }}$ century. Most critical to this transformation was Carolin's ability to escape from conceptual inertia imposed by prevailing taxonomic order, i.e., to think "out of the box." Based on his extensive field and morphological studies, he applied cladistic reasoning to reconstruct Portulacaceae taxonomy from square one. But neither empirical knowledge nor cladistic reasoning was by itself sufficient. Previous Portulacaceae taxonomic research was empirical, but it was constrained by noncladistic evolutionary dogma. Cladistic methods per se proved their impotence when applied vacuously and conditioned excessively upon classical noncladistic taxonomic order [56; cf. 57, 58]. Carolin understood that existing taxonomic units within classical Portulacaceae were constructed non-cladistically. They had no a priori utility for cladistic analysis except coincidentally. So he completely decomposed Portulacaceae to the 
species level before reconstructing it as cladistically determined. He also was careful to assure data availability/adequacy for each operational taxonomic unit.

Not unexpectedly, much of the refinement of the Carolin-Hershkovitz model of Portulacineae phylogeny owes to analysis of DNA sequence data. But this also benefitted from out-of-box thinking. In particular, the earliest molecular phylogenetic analyses of Caryophyllales [59-62] likewise were essentially mechanical and conditioned by classical taxonomic order. Classical familial circumscriptions evidently were presumed to reflect, if not monophyletic (as argued in [57] on the basis of weak and/or incorrect evidence), then at least homogenous and significantly diverged taxa. Thus, slowly-evolving DNA markers were sampled in one to a few proxy species per classically-conceived family.

Hershkovitz argued $[6,56]$ that classical Caryophyllales familial circumscriptions were unnatural and phylogenetically misleading. Partly to demonstrate this, [9] deliberately analyzed nominally interfamilial Portulacineae relations using a rapidly evolving DNA marker normally applied to infrageneric phylogeny. This demonstrated that some "interfamilial" divergences were less than "infrafamilial." Radical differences between the current phylogenetic and classical familial classification $[14,63]$ demonstrate that the argument of familial nonmonophyly made years earlier was correct, and that the counterargument for monophyly of classical families [57] was spurious. By the time of [63], this "discovery" was already "settled science" $[6,9,11,63,65]$.)

To be fair, much of the credit for current molecular phylogenetic knowledge is owed to the authors/inventors of the corresponding theory and technology, as well as providers of DNA samples and analytical services. This is because, by the late 1990s, available technology and analytical programs yielded purely mechanically a plausible phylogenetic estimate. This rendered empirical molecular phylogenetics largely an endeavor of "acquisition" more than "inquisition," viz. acquisition of specimens and the material wherewithal to run them through the mill. As Nobel laureate John Watson reportedly said, "any monkey could do it."

However, the superficial simplicity of modern genomic/computational systematics is-and must be-illusory. In particular, parametric complexity of evolutionary analysis is increased, not decreased. It adds, however conveniently packaged, dimensions from molecular genetics, mathematics, statistics, informatics, computation science — and philosophy. It subtracts nothing. More importantly, genomic/computational phylogenetic methods also impose order. However accurate is a phylogenetic tree, as ever, it canalizes subsequent evolutionary thinking. That evolutionary thinking must be questioned post-analytically. Much like modern powerful weaponry, powerful analytical methods can make powerful errors, or at least powerful oversights.

As an example in the present context, the Lewisiopsis morphological and molecular data demonstrate an idiosyncratic but significant result overlooked by linear method-oriented evolutionary 
thinking. This might reflect a methodologically-reinforced underlying preference to perceive evolution as a monotonic process whose understanding is limited only by data quantity and computational power. The emphasis on automated cladogram resolution possibly biases against consideration of idiosyncratic hybrid origins and other idiosyncratic but informative data behavior. Thus, [16] overlooked the possible significance of among-dataset conflicts. Likewise, [17] applied the "nuclear option" of whole genome phylogenetics in order to maximize cladogenetic resolution. But perhaps in the zeal to maximize data, [17] overlooked the glaring conflict with [16] in the position of Lewisiopsis. Branch length asymmetries with respect to Lewisiopsis and taxa in general were noted earlier in $[9,10,19]$, but not in the more recent, more data-laden, and computationally more sophisticated analyses of [16] and [17]. However, the last did apply methods that "correct" branch length asymmetries for the purpose of chronological dating. This means that branch length differences were perceived, but no evolutionary significance was afforded them. They required computational "correction" to facilitate interpretation. Likewise, $[16,17]$ did not detail the morphological peculiarities of Lewisiopsis or, in [16], taxa in general.

The view advocated here and in [2] is that advancing evolutionary knowledge remains an intellectual as much as a technological challenge. It depends upon escaping from conceptual order. This is because evolution itself is idiosyncratic and not constrained by the order that methodological dogma imposes on it. This view in no way dismisses the validity or utility of methods per se, provided that their assumptions and limitations are understood. An example is justification for pattern-based probabilistic phylogenetic reconstructive methods (e.g., [40]). It must be understood that probabilistic methods are restricted to parameters that are truly stochastic and sufficiently variable to be amenable to statistical analysis. It is useful, of course, if the stochasticity of this variation can be validated independently. For example, base substitution biases can be explained by empirical evidence for the biological cause of such bias and its stochasticity.

Likewise, it is understood (theoretically) that: (i) existing substitution parameter estimation methods do not account for all known (much less unknown) molecular evolutionary phenomena; (ii) there should be-and is-an inverse relation between the "globality" of evolutionary parameter estimates and their local accuracy; (iii) incidents of "less probable" evolution are, collectively, highly probable; and (iv) phylogeny captures an asymptotically infinitesimal portion of evolutionary natural history. The last statement emphasizes that molecular phylogenies are merely abstract one-dimensional pedigrees of derived from DNA sequences of extant individuals. They (might) corroborate sequential evolution of traits, but document little if anything else of events that transpired during the course of phylogenesis. To appreciate this, merely consider how much of Mesozoic seed plant evolution is documented by molecular phylogenetic analysis of extant taxon phylogeny. 
Hershkovitz

Montiaceae Phylogeny and Phylogeography

The significance of the preceding in the present context is that it likewise is understoodtheoretically-that conventional computational phylogenetic analysis (in all of its forms) merely calculates phylogenetic order given uniform methodological assumptions, parameter estimates, and algorithm [27]. Methodologically unpredictable idiosyncratic evolutionary events are overwritten. For the record, I do not assert that current estimates of Montiaceae are unreasonable or inaccurate. As generalized phylogenetic descriptions, much of the resolution probably is accurate. Rather, I assert that phylogenies can be only as accurate as their methods allow. For example, none of the essentially infinite number of possible phylogenies of 270 species and 20 subspecific taxa of Montiaceae can be true if even one of the clades has a hybrid origin [19; cf. 66]. And even if it assumed that half of the nodes now are resolved with reasonable certainty, this leaves correspondingly only less than infinite the number of possible phylogenies among the remainder.

However, theoretical and empirical knowledge of genetics and evolution render moot the ideal of fully resolving the phylogenetic tree of Montiaceae, Portulacineae, or life in general. It is known that organismal evolution sometimes is and sometimes is not, hence was or was not, tree-like. Even when treelike, diversification sometimes occurred too rapidly to recover the cladistic sequence. Here, overindulgence in phylogenetic analysis-beating the phylogenetic bush-cannot help but degenerate into the byzantine. Failure of data and methods to resolve phylogenies is more profitably interpreted as an indication of evolutionary phenomena not anticipated by analytical approaches. In other words, phylogenetic analysis profitably can be directed as a search for evolutionary idiosyncrasy as much as evolutionary order.

\section{PERSPECTIVES FROM CURRENT EVIDENCE FOR MONTIACEAE PHYLOGEOGRAPHY}

Hershkovitz [6] noted that the "portulacaceous alliance" (i.e., Portulacineae) partitioned into two groups whose members distributed mainly on opposing sides of the American cordillera: a western American and Australian group and an eastern American and African group. Carolin [3] derived a "reduced area cladogram" demarcating the same partition. However, in Carolin's phylogeny, the partitioning was repeated, whereas in Hershkovitz [6], it occurred once. Most of the taxa are southern hemisphere, but the east-west pattern maintains in both hemispheres. The phylogeny thus superficially suggested an ancient distribution in Pangaea (at least $180 \times 10^{6} \mathrm{ybp}$ ), then diversification primarily in Gondwana (at least $100 \times 10^{6} \mathrm{ybp}$ ), and persisting today in the various break-up products. A further observation was the latitudinal bias between the two partitions. Taxa of the western partition have an almost exclusively temperate to arctic distribution, whereas the eastern partition taxa are primarily tropical to warm temperate. 
Hershkovitz Montiaceae Phylogeny and Phylogeography

The geographic partitions described above superficially seemed to corroborate the posture of the vicariance phylogeography school, viz., the interpretation of historical land connections in terms of cladistic relations of modern taxa $[67,68]$. Vicariance-mediated diversification at least tacitly had been invoked for some southern hemisphere Portulacineae [3, cf. 66]. In this discussion, I use the term phylogeography mainly in the Cartesian coordinate sense, i.e., the interpretation of the transport mechanism of plants from point A to point B across the global landscape. Phylogeography more broadly also encompasses ecological dimensions of spatiotemporal organismal incidence, which will emerge later in the discussion.

Hershkovitz \& Zimmer [9, 10] corroborated the phylogeographic pattern evident from the morphological analysis, but also interpreted as pure coincidence the correspondence between portulacaceous phylogeny and ancient landmass configurations. In particular, intercontinental disjunctions among modern taxa appeared to be too recent to be explained by ancient landmass connections. Hershkovitz \& Zimmer also estimated a remarkably high LDD "rate" for Montiaceae given the apparent lack of a corresponding LDD adaptation [10]. This result further undermined the prevalent vicariance phylogeography philosophy, at least with respect to plants.

Antitropical temperate/polar infrageneric disjunctions of Montiaceae and numerous putatively recently-evolved angiosperm lineages conventionally were explained by LDD and/or contraction/expansion during major historical climate change cycles [69, 70; cf. 71]. The latter is plausible for the origin of North American Calandrinia menziesii and C. breweri, given the current range of $C$. ciliata in the cordillera from southern Mexico to northern Argentina. Cordilleran migration might also explain the origin of northernmost Andean Montia forms. Analogous historical latitudinal expansion of aridity [72] emerges as a possible explanation for antitropical disjunctions in Cistanthe and Calyptridinae.

Otherwise, philosophical aversion to “one-off” LDD explanations of antitropical disjunctions has advanced two alternatives. One is an appeal to hypothetical transitory ancient land bridges [67, 68; cf. 70, 72]. The other appeals to hypothetical widespread Pangaean ancestral species that differentiated cladistically following land area separations[73-75]. Concomitantly, [73-75] argue that current cladedating methods grossly underestimate the true age of clade origins. This view degenerates to tautology not unlike Biblical Creationism. It ignores ample evidence for dispersability inherent in the origin of recent oceanic island floras, and it requires that essentially all plant clades differentiated prior to the Pangaean separation..

Hershkovitz $[9,10]$ argued that Portulacineae diversified as recently as the latest Eocene to Miocene. More recent analyses [15-17] have calculated an eariler mid-Eocene origin. But even these estimates rendered untenable vicariance explanations of Portulacineae intercontinental disjunctions. 
Hershkovitz Montiaceae Phylogeny and Phylogeography

Moreover, the observed intercontinental and/or transoceanic disjunction divergence dates for different taxa do not coincide temporally. Disjunctions originated repeatedly throughout the Tertiary-Quaternary, most apparently Miocene or later [9, 10; cf. 15, 16; but see 17]. The latter observation is critical.

Hershkovitz [10] also emphasized that Montiaceae lack LDD-facilitating morphological specializations, such as winged, fleshy, or adhesive propagules. It is conceivable that the scarious floral apparatus of certain Calyptridinae species (e.g., Calyptridium monospermum and Philippiamra celosioides) could become aloft while still containing a seed. However, the distribution of this trait within these genera and the amphitropical prevailing wind patterns renders unlikely that disjunction of Calyptridinae originated this way. Heads [73] considered lack of dispersal mechanism as problematic in dispersalist explanation. But phylogenetic evidence for dispersal suggests that LDD is common, with or without a morphological mechanism. Hershkovitz [10] also remarked that the observed disjunctions must severely underestimate actual LDD incidence. These data, along with pervasive evidence for LDDmediated diversification in other angiosperms (e.g., Hawaiian plants and non-anthropogenic intercontinental distributions of many hundreds of species) render infinitely moot the vicariance-LDD question (see below). Thus, Hershkovitz [10] asserted that the evidence affords considerable a priori likelihood to LDD even in cases where vicariance is plausible (see below).

The inevitable acquisition of Hectorelleae DNA $[11,12]$ provided an interesting twist on phylogeographic interpretation. Its members occur in two insular terrains ca. $8000 \mathrm{~km}$ apart and otherwise lacking native Portulacineae: New Zealand (Hectorella) and the Kerguelen Islands in the subantarctic Indian Ocean (Lyallia). These terrains were physically connected in Gondwana, though very remotely, via Antarctica as late as the Cretaceous [76]. Applequist et al. [11] remarked that Hectorelleae phylogeography owed to LDD. But apparently they did not appreciate that the mid-Tertiary origin of Portulacineae [9, 10; cf. 15-17] a priori rendered vicariance implausible (see discussion of Rumicastrum above; note that Hectorelleae diverged later [16]).

Wagstaff \& Hennion [12] explained the Hectorelleae disjunction in terms of shorter jumps from a widespread ancestor in Antarctica. However, this explanation assumed an extreme estimate of the age of the Hectorella/Lyallia split at $18-25 \times 10^{6} \mathrm{ybp}$. This dating based on an estimated nucleotide substitution rate. Analyses of [14-16] estimated the Hectorelleae/outgroup split age at 20-30 x $10^{6} \mathrm{ybp}$. From likelihood-based phylograms in [12], it appears that Hectorelleae root to terminal divergence is much less than that of other Montiaceae, and that the Hectorelleae stem itself is rather short. Divergence between Hectorella/Lyallia likewise is minimal, evidently not much more than the stem divergence. Clearly, and perhaps not surprisingly given its slow growth, molecular evolution has advanced less in Hectorelleae than other Montiaceae. The trnK/matK sequences from the two taxa differ from each other by five substitutions and one indel in a poly-A repeat. A sequence from a Cistanthe species differs from that from 
Hershkovitz Montiaceae Phylogeny and Phylogeography

Lyallia by only seven substitutions and one indel. Still, the divergences are very low and render age dating difficult. One must consider the possibility of a founder effect difference.

Based on the older estimate in [12], Heads [74, 75] likewise suggested that Hectorella and Lyallia separated via shorter dispersals involving Antarctica and subantarctic islands. He also emphasized that this estimated age was much older than the origin of the modern arctic/alpine habitats of these taxa, which he interpreted as evidence of an earlier broader Hectorelleae distribution in Antarctica. Thus, Heads $[74,75]$ considered the estimate in [12] as evidence supporting his panbiogeographic interpretation.

Hectorelleae remain enigmatic phylogeographically and require further study. Hectorelleae diverged following divergence of, respectively, Rumicastrum and Calandrinia [16; cf. 17] Hectorelleae then are sister to the North American Montieae. These taxa comprise Montioideae [1]. Vicariance of Rumicastrum to Australia is doubted not only because of the timeframe, but because of its warm/aridadapted form, which renders unlikely its presence in southern Patagonia during the latest Eocene [1] (see also below). Calandrinia is another matter. It includes two clades, one alpine perennial and the other lowland temperate annual. Which form is derived remains uncertain [2]. But the perennial C. caespitosa complex includes cushion plants morphologically similar to Hectorelleae (though alpine cushion plants in many angiosperms share this form) and distributes to Tierra del Fuego [REF.]. And the Hectorelleae is sister to Montieae, whose first-diverging taxa are cold-adapted perennials.

These observations create the possibility that, following divergence of Rumicastrum, the ancestor of remaining Montioideae was cold-adapted and situated in southern Patagonia, which would have been cold at that time, ca. Oligocene (see below). From here would have diverged Calandrinia, which migrated northward as elevation and cooling of the northern Andes permitted [cf. 54, 70], Hectorelleae, and the ancestor of Montieae, which dispersed to North America. Then Hectorelleae would have dispersed to New Zealand and Kerguelen directly or via Antarctica. Whether Hectorelleae became widespread in Antarctica $[12,74,75]$ is not clear. Evidently, the plants are slow-growing, flower rarely, and produce few seeds that evidently do not germinate easily [12]. Hectorelleae would have had to migrate a total of about $16,000 \mathrm{~km}$ to situate themselves proximal to both New Zealand and Kerguelen. This undoubtedly is possible over the course of many millions of years, but, in this case, intercontinental LDD would seem to be faster and no less likely. There is also the possibility that the LDD vector was glacial.

An alternative to the preceding is a scenario whereby the Hectorelleae ancestor was more warmadapted and dispersed directly to New Zealand, where it evolved its alpine/arctic ecomorphology in situ as this habitat developed more recently in New Zealand [75]. Such a scenario has been argued for the origin of the central Andean alpine genus Oriastrum (nee Chaetanthera; Asteraceae; Mutiseae [54]). These alternatives might be evaluated with whole genome methods. Estimation of the arrival date to New 
Hershkovitz Montiaceae Phylogeny and Phylogeography

Zealand and Kerguelen might be possible using coalescent models at the genomic scale. This would require, among other things, not only a reasonable estimate of generation time, but also an assumption that this has been constant over time.

Regardless of whether Hectorelleae arrived to New Zealand and Kerguelen via Antarctica or directly, at least two LDD events were required, unless, as [74, 75] argues, molecular dating estimates are grossly erroneous. As it turns out, distance per se does not favor the former over the latter, because the dispersal potential of "nonstandard" mechanisms is fat-tailed and does not deteriorate normally with distance (see below). And, given enough time, nonstandard mechanisms are more likely to result in LDD.

More importantly, the Hectorelleae LDD evidence data bolsters the argument in $[9,10]$ for a high rate of LDD-mediated diversification among Montiaceae. The data add two more instances of LDD while adding only two more species to Montiaceae. Moreover, Hectorelleae appear even less "LDD-disposed" than other Montiaceae. While also lacking dispersal mechanisms, other disjunct Montieae taxa at least produce large numbers of seeds per generation, mostly orders of magnitude more than Hectorelleae. Thus, Hectorelleae emerge among candidates for an angiosperm taxon a priori least apt to disperse $8000 \mathrm{~km}$ (see also below). Applequist et al. [11] evidently did not appreciate the broader significance of their Hectorelleae data. They mentioned a few other examples of LDD among Portulacineae, but did not mention the earlier arguments $[9,10]$ for LDD explanation of essentially all Portulacineae intercontinental/transoceanic disjunctions.

Hectorelleae helps demonstrate that the LDD "pattern" transcends phylogenetic level. With Hectorelleae included, Montioideae alone manifest the entire western/southern "pseudo-Pangaean" distribution: North America (most Phemerantheae and Montieae spp.), South America (most Cistantheae and Calandrinia spp.), Australia (Rumicastrum), and, with Hectorelleae, New Zealand and the Kerguelen Plateau. Other Portulacineae also include endemic taxa in North America and at least two Gondwanan regions (Cactaceae, Anacampserotaceae, Portulacaceae, Talinaceae). Much of the pattern repeats in the genus Montia alone, a relatively young clade comprising about 20 species, with endemic taxa in North America, South America, and Australia/New Zealand. (O'Quinn [78] argued that Montia howellii in North America originated as a recent human-mediated introduction of a New Zealand species. While phylogenetic evidence strongly supports this interhemispheric disjunction, DNA sequence divergence is considerable and likely would date the separation to $10^{6}-10^{7}$ years. Alternatively, a true separation on the order of $10^{2}$ years would seriously challenge the validity of molecular dating methods in general.)

In 2018, Hancock et al. [17] suggested, with skepticism, that Rumicastrum arrived overland to Australia from South American via Antarctica. They cited as circumstantial evidence their age-dating of the Rumicastrum split to ca. $30 \times 10^{6} \mathrm{ybp}$, slightly younger than the final separation between Australia and Antarctica at ca. $33 \times 10^{6} \mathrm{ybp}$. Their skepticism is warranted. Their Montiaceae age-dating, while 
Hershkovitz Montiaceae Phylogeny and Phylogeography

1

using the identical procedure as [16], yielded a substantially older origin, which the authors did not address. In [17], the first Montiaceae crown dates to ca. 39 x $10^{6}$ ybp; in [16: Fig. 3], it appears to be ca. $34 \times 10^{6}$, with corresponding reductions in the age of Rumicastrum. The younger age would prohibit overland migration from Antarctica. As both works note, however, the method applied can be unreliable. Greater plausibility of the estimate in [17] might be argued on the basis of its much larger loci and base sampling.

But even with the older estimate, overland vicariance, even if not impossible, is implausible. The timing at the Antarctica-Australia connection cuts very close, and presumably requires establishment of the ancestor in Antarctica at some time prior to the final split. At the same time, it requires the protoRumicastrum lineage to have entered Antarctica from South America even earlier and migrated to the opposite side of the continent. The shortest distance between these points is a then-unlikely $5000 \mathrm{~km}$ migration path across then-cold central Antarctica. A more tolerable route along the continental periphery is approximately $10,000 \mathrm{~km}$.

However, the required South America-Antarctica connection itself is more problematic. First, the connection was a narrow isthmus, in contrast to the continent-wide Australia-Antarctica connection. Second, a seaway is believed to have developed over the continental shelves at ca. $55 \times 10^{6} \mathrm{ybp}$ [79], which is considerably older than the highest estimate of the Montiaceae crown divergence at ca. $40 \times 10^{6}$ ybp [17]. Short-distance dispersals might have been possible until the Miocene [79], but the narrowness of the connection remains problematic. Third, by $30 \times 10^{6} \mathrm{ybp}$, the warm humid Eocene Antarctic climate had degenerated into a cold one [80]. It must be recalled that the earliest-divergent Montiaceae, Phemeranthus and Cistanthe, like their nearest Portulacineae outgroups, are warmer and arid-adapted [16: Fig. 3]. The Cistantheae distribution centers in northernmost Patagonia, ca. $4000 \mathrm{~km}$ to the north. These data suggest the impossibility of overland migration of a warm- and arid-adapted proto-Rumicastrum $13,000 \mathrm{~km}$ to Australia in the timeframe of interest. Moreover, recalling other undisputable LDD events among Montiaceae (especially Hectorelleae), other Portulacineae, and angiosperms in general, a vicariance explanation for Rumicastrum does not merit the inherent parsimony advantage that vicariance advocates presume.

The evidence for promiscuous LDD-mediated diversification presents a paradox, however. Montiaceae and other Portulacineae present numerous tantalizing examples of disjunction/distribution that resonate with the vicariance narrative. But the promiscuous LDD narrative predicts that distributions should be more cosmopolitan and not manifest their tantalizing patterns. Besides the pseudo-Pangaean patterns within Montiaceae, another is itself the sister relation of Montiaceae to other Portulacineae. This partition separates "core" Montiaceae of cis-cordilleran western America from primarily trans-cordilleran American and African Portulacineae. The basal divergence of Montiaceae separates trans-cordilleran 
Hershkovitz Montiaceae Phylogeny and Phylogeography

North American Phemeranthus from cis-cordilleran South American Montiaceae. The basal split of Portulacineae separates largely east Gondwanan Didiereaceae from more central Gondwanan taxa. Evidently, the few isolated and morphologically "primitive" Anacampserotaceae occur in North America, South America, and Australia, separating these from the more diverse and derived African clade [81]. The basal split of Portulaca separates a few morphologically "primitive" Australasian relicts from the rest of the genus $[82,83]$. Cactaceae are a large almost exclusively American family. Suitability of habitat would not seem to explain these disjunction/distribution patterns, as suitable habitats for members of both the eastern and western Portulacineae groups occur on both sides of the phylogeographic partition. This is especially evident for Montiaceae species habitats: similar montane/alpine, Mediterranean-climate, and desert habitats occur in Europe, southwest Asia, and southern Africa.

But a more detailed examination reveals notable exceptions to the Portulacineae phylogeographic pattern. Endemic Cactaceae and Portulaca species occur in Chile and California; these are evidently recent colonizations. Claytonia diversified westward to northeast Asia and eastward to the eastern North American seaboard. The Montia fontana species complex is essentially cosmopolitan. However "primitive," the disjunct Anacampserotaceae and Portulaca taxa are of mid-Miocene age, which means that they dispersed to Africa. And several Portulacineae species, including Montiaceae, have expanded more globally anthropogenically. These include species of Anredera, Basella, Talinum, Portulaca, many Cactaceae, and, among Montiaceae, Calandrinia, Cistanthe, Claytonia, Montia, and Phemeranthus [1].The pattern, therefore, does not have a common historical phylogeographic cause-or an obligatory phylogeographic effect. Why, then, does a pattern appear at all?

Phylogeographic pattern-sharing might hold clues for explaining the infrequent eastward diversification of Montiaceae. South American Montiaceae genera appear to share a phylogeographic pattern with numerous angiosperm genera: species diversity concentrated in and mostly endemic to Chile, a few species crossing the border into adjacent territories, and few, if any, completely non-Chilean species [70]. But, again, closer scrutiny reveals that the shared pattern is consequent to phylogeographic convergence. Different taxa have attained the "Chilean" pattern in spatiotemporally and phylogenetically different ways [70]. It is not so clear, therefore, that phylogeographic pattern-sharing is strictly a function of phylogenetic pattern-sharing or geographic distance and connectedness. Other factors, such as ecological similarity, may have greater weight.

The case of Chile is special, because of its historical ecological isolation and distinctiveness, narrowness, steep ecological gradients across short distances, and instability. This would result in greater extinction, because there is not, as in broader and more uniform continental areas, a nearby pool of germplasm to repopulate local areas devastated by ecological disasters. This, in turn, offers opportunities for LDD invasion. Naturally, the invaders will include the most pre-adapted taxa from ecologically 
Hershkovitz Montiaceae Phylogeny and Phylogeography

similar habitats, e.g., mediterranean, desert, and alpine. More importantly, this scenario depends upon a high inherent LDD likelihood, which evidence from Montiaceae and other taxa now corroborate. Only the inherent implausibility of LDD afforded by vicariance phylogeographic philosophy [67, 68, 73-75] obligated otherwise implausible or counterevidenced scenarios.

The ecological scenario also helps explain the anti-Chilean pattern, i.e., the paucity of Chilean lineages in trans-cordilleran American and the eastern hemisphere. As noted above, habitats may be similar and some taxa indeed have crossed the phylogeographic partition in both directions. However, other land areas do not share Chile's geographic peculiarities. Their ecoregions are larger and/or ecological gradients are not as steep and/or their climatic stability is greater. Accordingly, their vegetation is more stable and more readily repopulated following localized ecological disasters.

Coincidentally, Montiaceae appears to be an exception to the rule. Following the split of transcordilleran Phemerantheae, the root of the remaining family seems to be present day northern Chile. From here occurred multiple LDD events that established lineages on other remote land areas, evidently involving also secondary LDD events from those areas. One species, Montia fontana, eventually made its way back to Chile. I cannot think of another lineage originating in Chile that has been so successful globally. Whether or not this success owes to traits evolved in Chile's challenging ecological conditions is not clear.

I interject here that this and similar phylogeographic patterns might be somewhat an illusory artifact of species diversity. In particular Montiaceae diversity is considerable and comparable in North America and South America. Mainly because of Rumicastrum, Australasian diversity also is considerable. This disjunct diversity is possibly what calls attention to the pattern. It would be less evident if only single species were so geographically removed. But this diversity is consequent to many factors unrelated to disjunction per se. For example, genetic divergence within South American clades is very low (see above). By whatever mechanism, it appears that Andean region diversity was achieved recently over a relatively short time period [19]. Before that, Chilean Montiaceae diversity may have been much less than that already achieved in North America. In other words, Montiaceae might have been perceive as a primarily North American lineage. It is important to appreciate that diversification of extant Montiaceae occurred at different timescales.

Thus, ignoring Phemeranthus, the phylogeny suggests that the Andean lineages diverged before North American Montieae, but extant Montieae genera diversified before diversification of the extant Andean genera. Moreover, the Andean lineages apparently diverged 25-32 x $10^{6}$ ybp [15, 16: Fig. 2; 17 : S18], long before the final uplift of the Andes and development of the current Mediterranean climate [54]. At that time, geographic and ecological partitioning of South America was far less pronounced. What were these Andean lineages "doing" during the Miocene? How many species were there? What forms did 
they have? Were they less arid-adapted? Did they extend to eastern South America? The answers may never be known. All that is known is that some lineages survived and diversified relatively recently into modern Andean habitats that did not exist when the lineages originated. This is circumstantial. The ancestors had not the foresight to plan and prepare for the Andean uplift.

In conclusion, Montiaceae and other Portulacineae demonstrate the significant role of unique rather than concerted events in explaining phytogeographic distributions. Donoghue [71] recognized the contribution of DNA-based phylogenetics towards testing and debunking phylogeographic dogmas. At the same time, he emphasized that the explanatory power of phylogeographic theory rests not in one-off explanations, but in commonality of cause. Sharing phylogeographic cause necessarily manifests in sharing of phylogeographic patterns (non-random distributions). But is the contrapositive necessarily true? Does sharing phylogeographic pattern implicate shared phylogeographic cause?

Moreira Muñoz [70], presumably among others, referred to the philosophical and perceptual bases of phylogeographic pattern recognition. A detailed discussion of the philosophy and psychobiology of pattern perception and pattern explanation is beyond the scope of the present work. Suffice it to say that pattern perception and explanation are default neurobiological processes. The mind looks for and explains patterns not because the patterns and explanations are real, but because the mind needs predictability to function. Humans consciously prefer to perceive patterns, explain them, and believe their explanations, even when aware that these are false. A prime example is "constellations" and the predictive power afforded them. Even university-educated humans in scientifically advanced societies affirm astrology.

Cartesian phylogeographic patterns are not entirely imagined, however. But even when patterns are "true," or at least "statistically significant," their explanation need not reflect a single common cause [84]. Thus, pattern recognition is, at best, only part of the solution in phylogeographic theory, and it also is part of the problem. Humphries \& Parenti $[67,68]$ evidently perceptually favored uniformity of pattern and universality of explanation. Donoghue [71] evidently appreciated the role of idiosyncrasy in falsifying explanatory dogma, but manifests discomfort in the face of consequent pattern degeneration, hence unifying laws.

Notably, interpretation of global phylogeographic patterns has gone full circle in three decades. Prior to development of vicariance phylogeography, plant disjunctions commonly were explained by dispersal [e.g. 85, cf. 71]. The presence of diverse floras on remote young oceanic islands (especially Hawaii) at least validated dispersal as a potent phylogeographic process. Similarity of intercontinentally disjunct plant (as opposed to terrestrial animal) species provided circumstantial evidence.

But by the 1990s, vicariance had become the default explanation in phylogeography (e.g., [67, 68]) and LDD explanations were derided as unscientific. In fact, at that point, vicariance dogma was 
considered so robust that plant distributions were applied in reverse to develop and adjudicate hypotheses of plate tectonics and ancient land bridges (e.g., [67, 68]). Ironically, unlike LDD in the case of young oceanic islands, it was not LDD, but rather vicariance, that was not corroborated scientifically by chronological evidence.

By about 2010, thanks to molecular dating, the tide shifted again, and LDD re-emerged as a principal explanation for plant disjunctions [70,72]. But much earlier, even paleontologists criticized vicariance dogma. Pole [86] heretically predicted that disjunct elements of the New Zealand flora reflected LDD. Tay [87] summarized molecular evidence showing Pole [86] was correct, documenting about 50 instances of LDD versus about five instances of vicariance. More globally, LDD was deduced to explain disjunctions even in clades old enough to be vicariant [88].

Based on the inferred frequency of LDD disjunctions relative to cladogenetic events, [10] conceived of dispersability informally as a likelihood function, comparing it to a DNA base substitution rate: rare, but over time, with a significant cumulative likelihood of occurring. Moreover, [10] noted that a dispersal likelihood is independent of a vicariance (i.e., normal overland migration) likelihood. This suggestion was consequent to the seemingly obvious observation that whatever explained taxon ranges in contiguous lands, this could not explain discontiguous ranges over water. Thus, even disjunct ranges in contiguous lands might owe to LDD. Just as importantly, evidence that essentially all disjunctions among Portulacineae represented LDD effectively discredited the privilege afforded to vicariance explanations.

Coincidentally, shortly thereafter, several researchers proposed formal multiparameter likelihood phylogeographic models not unlike complex DNA substitution models [89-93]. All emphasized the significant role of LDD in explaining global phylogeogtraphy. One line of research in particular [91, 92] emphasized that LDD and "standard" plant dispersal functions generally are distinct. In other words, standard dispersal functions reflect the normal dispersal mechanism of a taxon, which may or not facilitate LDD. This is consistent with the proposal in [10]. Standard dispersability likelihood tends towards zero with increasing distance. The LDD function, in contrast, reflects nonstandard and less predictable dispersal mechanisms capable of abruptly dispersing propagules indefinitely long distances. Consequently, the nonstandard function is fat-tailed with respect to dispersal distance. Moreover, by nonstandard dispersal mechanisms, the cumulative probability of LDD increases with cumulative seed load, whereas by standard mechanisms, it does not. This, in turn, offers an explanation of the LDD success of taxa like Montiaceae that lack a standard dispersal adaptation.

It may be surprising, given the molecular-based evidence for high LDD frequency even in taxa lacking dispersal adaptation, that as recently as 2011, evidence for a single example of amphipolar LDD was touted in the journal Nature as a significant discovery [71]. Moreover, the example was not unexpected, given that it involved a taxon with fleshy fruits known to be dispersed by amphipolarly 
migrating birds. Donoghue [71] took the occasion to elegantly summarize the history of debate over intercontinental plant disjunction mechanisms, but did not emphasize that there was never scientific reason to doubt, and always every reason to believe, that multiple mechanisms occur and that LDD was a common feature of plant phylogeography. In the case of morphologically very similar species whose disjunction matches the migratory flight path of birds that eat their fruits, LDD seems to be a no-brainer. Only earth-shattering fossil and/or molecular evidence could have nudged the verdict in the direction of vicariance. Thus, if the essay in [71] revealed anything noteworthy, it was that obsolete dogma and a long-since germane but now contrived and byzantine debate persisted lime-lighted in systematic and evolutionary biology well into the 21 st century.

Nonetheless, as in all of science, advancement of phylogeographic theory rests on predictability. This can be accomplished in two ways. One is the blanket approach of comparing fit of empirical data patterns to alternative explanations and accepting the most parsimonious. The other is the destructive approach of falsifying patterns/explanations one data point at a time (i.e., proving one-off explanations). It is true that general explanations make predictions and one-off explanations do not. But exceptions to general explanations should be perceived as troublesome and not swept into the dustbin of residual variance, as demonstrated above and especially in [2]. Alternatively, analysis of one-off explanations may reveal unappreciated commonalities that ultimately yield better general explanations. Thus, [10] argued that the evidence demonstrates that LDD-mediated diversification is not a one-off explanation, but a phenomenon whose empirically determined frequency validates a priori its expectation in phylogeographic reconstruction. This is true even if vicariance is plausible and no dispersal mechanism is obvious. Subsequent research on many taxa has corroborated this view and refocused phylogeographic research in new directions (see below).

The evidence for LDD as a principal explanation for plant disjunctions left plant phylogeography in a quandary. In particular, vicariance offered a simple and uniform causal explanation of apparent phylogeographic patterns. LDD does not. What other simple and uniform theoretical framework can replace it? Several researchers [89-93] advocate a multi-parameter approach that can be described as epiphylogenetic ecological community assembly (see below). Thus, parameters of plant phenotypes and environments can be incorporated into phylogeography as a way to study simultaneously the evolution of all parameters that effect plant movements. Phenotypic and environmental parameters thus can constrain or relax likelihoods of deduced changes in taxon ranges. In this way, recurring patterns of \{phylogeny $\mathrm{x}$ phenotype X ecology X movement\} patterns can be detected, with the objective of discovering multidimensional commonality of cause. Formal probabilistic models described in [90, 91] incorporate such ideas. 
Hershkovitz Montiaceae Phylogeny and Phylogeography

In many ways, the approach suggested by [89-93] is an advance over narrative and/or singleparameter explanations of phylogeographic patterns. Instead of focusing on single parameters, it facilitates delimitation of any and all conceivable parameters that might affect phylogeography. These include not only dispersal vectors and adaptations, but suitability of destination habitats given the ecology in the source habitat. Even relatively rare phenomena can be incorporated. Ostensibly, likelihoods of different scenarios can be compared. Such an approach would be useful in the case of the Chilean flora.

At the same time, whatever the heuristic value of the approach, it is unlikely to "prove" specific hypotheses in practice. It is prone to statistical artifacts articulated in this work and in [2]. Proposed parameter categories are complex and render parameter evaluation subjective. As parameter richness increases, so do the number of data categories, hence the fewer the number of data points per category, hence the higher the variance and the less precise and accurate the estimate. Phylogeographic histories that are rare or unique cannot be modeled at all. They will be forced to conform to more frequent histories, possibly reinforcing support for the predominance of those histories. In particular,, lumping parameters for statistical expedience distorts data [2|. Finally, as elaborated more in [2] (see also [84, 95]), almost any reasonable pattern-generating model will tend to fit data better than a random pattern null model, such that the pattern-generating model will bias analysis in its own favor. In other words, the model will as much impose as test itself. As a further complication, the parameter-rich likelihood approach necessitates Bayesian methods, which introduces the same hazards discussed above and in [2].

Consequently, the model-based approach at best will permit evaluation of general hypotheses about phylogeography, but will not predict unequivocally phylogeographic histories or trajectories. This is especially because of theoretical predictions that individual phylogeographic histories often reflect "nonstandard" (effectively, one-off) dispersal phenomena [90]. Thus, the parameters most precisely estimated statistically may be irrelevant in explaining many individual phylogeographic histories.

One can compare statistical phylogeographic explanation with that of a traffic jam along a stretch of a major highway. Can the explanation derive from the commonality of the joint presence of the vehicles? Perhaps, if the vehicles have a proximal origin and a common destination, e.g., a major sporting event. But suppose each departed at a different time from divergent origins and had divergent destinations and unexpectedly converged at the same point at the same time. Or suppose a distressed small aircraft made an emergency landing on the highway, causing a jam that would not have occurred otherwise. How many model parameters are required to test all possible historical causes for a traffic jam? How much data is required? Does increasing parameter richness not converge on "narrative"? Can statistical analysis discriminate between parameter/data-laden complex and non-nested explanations? Is it reasonable to combine similar but distinct parameters/data in order to improve statistical precision? Is the resulting most probable explanation the most accurate? These questions are explored in greater detail in [2]. 
Hershkovitz Montiaceae Phylogeny and Phylogeography

More troublesome, inevitably the multi-parameter Bayesian approach will be applied dogmatically to broad scale phylogeographic analysis that cannot avoid parameter/data oversimplification. To the degree that the application is purely heuristic and a means of merely statistically describing phylogeographic patterns rather than proving phylogeographic hypotheses, this would be useful. Unfortunately, the scientific endeavor spurns the predicate of description and demands the predicate of proof. The result likely will be prominently-published unwarranted conclusions, with as many authors as necessary to insure that all benefit socioeconomically while none bear any responsibility. These conclusions, in turn, will incarnate as highly-cited truth. Ironically, a computational approach developed precisely to supersede a narrative approach ultimately will validate the narrative approach. At the same time, perhaps that validation renders worthwhile the computational effort.

To encapsulate, phylogeography, like evolution generally, is not constrained by statistical analytical assumptions and parameterizations imposed upon it. Put another way, assumptions and parameters are requisite for statistical analysis and not evolution. But both methodological and psychobiological tendencies naturally exaggerate pattern simplification and minimize or omit evidence for idiosyncratic evolution. Finally, even statistically significant correlations can be consequent to historical accident [84]. Different accidents might have yielded different correlations. The second part of this work [2] argues that such statistical approaches to evolutionary analysis are useful if applied heuristically, and if inferred correlations are interpreted not as evolutionary laws or explanations, but as statistical descriptions.

In summary, the complexity of phylogenetic analysis must be considered trivial compared to epiphylogenetic analysis, including phylogeography. Here, I borrow the term epiphylogenesis from the realm of philosophy of the human condition. The concept is attributed to philosopher Bernard Stiegler, and refers to processes that become parametrically integral to human evolution but are not genetically programmed by it, in particular technology [95]. Epiphylogenetic processes are supposed to facilitate escape from human phylogenetic constraints. Analogously, processes that affect plant distributions (including plate tectonics) are not genetically programmed or phylogenetically preordained. They are epiphylogenetic, yet become integral to plant evolution and facilitate escape from prior phylogenetic constraints.

Phylogeny, at least, reduces causally to the processes of mutation and reproduction. Phylogeographic analysis had attempted to reduce phylogeographic pattern explanation to the process of plate tectonics. This having failed, other workers [89-93] suggest an expanded but no less reductionist approach to accommodate any/all conceivable epiphylogenetic processes. But epiphylogenetic processes are infinite and irreducible. Thus, commonality of epiphylogenetic causality is possible but unlikely. More likely, patterns apparent in different parametric dimensions will conflict. In any case, as emphasized 
Hershkovitz Montiaceae Phylogeny and Phylogeography

1

2

3

4

5

6

7

8

9

10

repeatedly here and in [2], evolution is not constrained by pattern. Moreover, evolution does not cause organisms to be similar. Axiomatically, it causes them to be different. Thus, phylogeography indeed is a collection of one-off histories. As Moore and Donoghue [96] suggest, phylogeography is a consequence of "[the right organism with the right descendents "being in the right place at the right time. This interpretation applies to all evolutionary phenomena. This is consequent to PEI [2].

\section{Full authored names of subgeneric taxa cited in this work}

Calandrinia breweri S. Watson; Calandrinia caespitosa Gillies ex Arn.; Calandrinia ciliata (Ruíz \& Pav.) DC; Calandrinia menziesii (Hook.) Torr. \& A. Gray; Calandrinia sect. Amarantoideae Reiche [三 Philippiamra]; Calyptridium ambiguum (S. Watson) Hershk.; Calyptridium monospermum Greene; Calyptridium sect. Spraguea Hershk., comb. nov. इ Spraguea Torr., Smithsonian Contr. Knowl. 6: 4. 1853; Calyptridium sect. Thingia Hershk., comb. nov. $\equiv$ Thingia Hershk, Preprints 2018; 2018080496;

Cistanthe sect. Rosulatae (Reiche) Hershk.; Lewisia sect. Cotyledon Hohn ex B. Mathew; Montia fontana L.; Montiopsis cistiflora (Gillies ex Arn.) D. I. Ford; Montiopsis subg. Dianthoideae D. I. Ford; Philippiamra calycina (Phil.) Hershk.; Philippiamra celosioides (Phil.) Kuntze.

\section{Abbreviations}

BE: Bayesian estimation; BP: bootstrap proportion; LDD: long-distance dispersal; ML: maximum likelihood; MP: maximum parsimony; PEI: Principle of Evolutionary Idiosyncraticity; PP: posterior probability.

\section{Competing interests}

The author declares no competing economic or political interests.

\section{Funding}

This work received no external funding.

\section{Authors' contributions}

MAH executed this work in its entirety. 
Hershkovitz Montiaceae Phylogeny and Phylogeography

1

\section{Acknowledgements}

Elaboration of the present work would not have been possible except for the generous support and dedicated efforts of Katia Chechelnitzky, Sandra Steuermann, and Gabriela Feldman of Fundación Reshet in Chile (www.reshet.cl). I gratefully acknowledge Mary Endress for helpful review of a preliminary version of this work and encouragement. I also gratefully acknowledge the many Montiaceae researchers who generously shared with me (via their journal publications) their data and interpretations.

\section{References}

1. Hershkovitz MA. Synopsis of a new taxonomic synthesis of Montiaceae (Portulacineae) based on rational metadata analysis, with critical new insights on historically poorly understood taxa and a reevaluation of historical biogeography. Preprints 2018; 2018080496 https://doi.org/10.20944/preprints201808.0496.v1

2. Hershkovitz MA. Perspectives from Montiaceae (Portulacineae) evolution. II. Phenotypic and ecological evolution. To be posted.

3. Carolin RC. A review of the family Portulacaceae. Austral J Bot. 1987;35:383-412. https://doi.org/10.1071/BT9870383

4. Carolin RC. Portulacaceae In: Kubitzki K, Bittrich V, Rohwer J, editors. The families and genera of vascular plants. Vol. 2. Berlin, Heidelberg, New York: Springer; 1993. p. 544-555.

5. Hershkovitz MA. Phylogenetic assessment and revised circumscription of Cistanthe Spach (Portulacaceae). Ann Missouri Bot Gard. 1991;78:1009-1021. http://www.jstor.org/stable/2399741

6. Hershkovitz MA. Revised circumscription and sectional taxonomy of Calandrinia Kunth and Montiopsis Kuntze (Portulacaceae) with notes on phylogeny of the portulacaceous alliance. Ann Missouri Bot Gard. 1993;80:333-365. http://www.jstor.org/stable/2399789

7. Pax F, Hoffmann K. Portulacaceae. In: Engler A, Harms H, editors, Die natürlichen Pflanzenfamilien. 2nd ed, vol 16c. Leipzig: Wilhelm Engelmann; 1934. p. 234-262.

8. McNeill J. Synopsis of a revised classification of the Portulacaceae. Taxon 1974;23:725-728. http://www.jstor.org/stable/1218433

9. Hershkovitz MA, Zimmer EA. On the evolutionary origins of the cacti. Taxon 1997;46:217-242. http://www.jstor.org/stable/1224092

10. Hershkovitz MA, Zimmer EA. Ribosomal DNA evidence and disjunctions of western American Portulacaceae. Mol Phyl Evol. 2000;15:419-439. https://doi.org/10.1006/mpev.1999.0720 
Hershkovitz Montiaceae Phylogeny and Phylogeography

11. Applequist WL, Wagner WL, Zimmer EA, Nepokroeff M. Molecular evidence resolving the systematic position of Hectorella (Portulacaceae). Syst Bot. 2006;31:310-319. https://doi.org/10.1600/036364406777585900

12. Wagstaff SJ, Hennion FO. Evolution and biogeography of Lyallia and Hectorella (Portulacaceae), geographically isolated sisters from the Southern Hemisphere. Antarctic Sci. 2007;19:417-426. https://doi.org/10.1017/S0954102007000648

13. Nyffeler R, Eggli U. Disintegrating Portulacaceae: a new familial classification of the suborder Portulacineae (Caryophyllales) based on molecular and morphological data. Taxon 2010;59:227240.

14. Hernández-Ledesma P, Berendsohn WG, Borsch T, von Mering S, Akhani H, Arias S, CastañedaNoa I, Eggli U, Eriksson R, Flores-Olvera H, Fuentes-Bazán S, Kadereit G, Klak KC, Korotkova N, Nyffeler R, Ocampo G, Ochoterena H, Oxelman B, Rabeler RK, Sanchez A, Schlumpberger BO, Uotila $\mathrm{O}$. A taxonomic backbone for the global synthesis of species diversity in the angiosperm order Caryophyllales. Willdenowia 2015;45:281-383. https://doi.org/10.3372/wi.45.45301

15. Arakaki M, Christin P-A, Nyffeler R, Lendel A, Eggli U, Ogburn RM, Spriggs E, Moore MJ, Edwards EJ. Contemporaneous and recent radiations of the world's major succulent plant lineages. Proc Nat Acad Sci USA. 2011;108:8379-8384. https://doi.org/10.1073/pnas.110062/81089

16. Ogburn RM, Edwards EJ. Life history lability underlies rapid climate niche evolution in the angiosperm clade Montiaceae. Mol Phylogenet Evol. 2015;92:181-192. https://doi.org/10.1016/j.ympev.2015.06.006

17. Hancock LP, Obbens F, Moore AJ, Thiele K, de Vos JM, West J, Holtum JAM, Edwards EJ. Phylogeny, evolution, and biogeographic history of Calandrinia (Montiaceae). Amer J Bot. 2018;105:1-14. https://doi.org/10.1002/ajb2.1110

18. Smith SA, Brown JW, Yang Y, Bruenn R, Drummond CP, Brockington SF, Walker JF, Last N, Douglas NA, Moore M J. Disparity, diversity, and duplications in the Caryophyllales. New Phytol. 2018;217:836-854. https://doi.org/10.1111/nph.14772

19. Hershkovitz MA. Evolution of western American Portulacaceae in the Andean region. Gayana 2006;63:13-74. http://dx.doi.org/10.4067/S0717-66432006000100002

20. Price T. Phylogeny and evolution of Phemeranthus (Montiaceae) in North American xeric habitats. $\mathrm{PhD}$ dissertation, Washington University, St Louis; 2012. \#\#\#\#\#[Electronic theses and dissertations, Paper 724 http://openscholarship.wustl.edu/etd/724].

21. O’Quinn R\#\#\#\#\#[L], Hufford L, Meerow AW. Molecular Systematics of Montieae (Portulacaceae): implications for taxonomy. Biogeogr Ecol Syst Bot. 2005;30:314-331. https://doi.org/10.1600/0363644054223594 
Hershkovitz Montiaceae Phylogeny and Phylogeography

22. Stoughton TR, Kriebel R, Jolles DD, O'Quinn RL. Next-generation lineage discovery: A case study of tuberous Claytonia L. Amer J Bot 2018;105:536-548. https://doi.org/10.1002/ajb2.1061

23. Guindon S, Dufayard J, Lefort V, Anisimlov M, Hordijk W, Gascuel O. New algorithms and methods to estimate maximum-likelihood phylogenies: assessing the performance of PhyML 3.0. Syst Biol. 2010;59:307-321. https://doi.org/10.1093/sysbio/syq010

24. Felsenstein J. Confidence limits on phylogenies: an approach using the bootstrap. Evolution 1985;39:783-791. https://doi.org/10.1111/j.1558-5646.1985.tb00420.x

25. Sanderson MJ. Objections to bootstrapping phylogenies: a critique. Syst Biol. 1995;44:299-320. https://doi.org/10.1093/sysbio/44.3.299

26. Alfaro ME, Holder MT. The posterior and the prior in Bayesian phylogenetics. Ann Rev Ecol Evol Syst. 2006;37:19-42. https://doi.org/10.1146/annurev.ecolsys.37.091305.110021

27. Kumar S, Filipski AJ, Battistuzzi FU, Kosakovsky Pond SL, Tamura K. Statistics and truth in phylogenomics. Mol Biol Evol. 2012;29:457-472. https://doi.org/10.1093/molbev/msr202

28. Simmons MP, Norton AP. Divergent maximum-likelihood-branch-support for polytomies. Mol Phylogen Evol. 201473:87-96. https://doi.org/10.1016/j.ympev.2014.01.018

29. Bååth R. The non-parametric bootstrap as a Bayesian model. http://tinyurl.com/bayes-bootstrap; 2015.

30. Yang Z, Zhu T. Bayesian selection of misspecified models is overconfident and may cause spurious posterior probabilities for phylogenetic trees. Proc Nat Acad Sci USA 2018;115:1854-1859. https://doi.org/10.1073/pnas.1712673115

31. García-Sandoval R. Why some clades have low bootstrap frequencies and high Bayesian posterior probabilities. J Israel Ecol Evol. 2014;60:41-44. https://doi.org/10.1080/15659801.2014.937900

32. Autzen B. Bayesian convergence and the fair-balance paradox. Erkenntnis 2018;83:23-263. https://doi.org/10.1007/s10670-017-9888-0

33. Dragicevic P. Fair statistical communication in HCI. In: Robertson J, Kaptein M, editor. Modern statistical methods for HCI. Switzerland: Springer; 2016. p. 291-330.

34. Swofford DL, Olsen GJ, Waddell PJ, Hillis DM. Phylogenetic inference. In: Hillis DM, Moritz C, Mable BK, editors. Molecular888 Systematics. 2nd ed. Sunderland (MA): Sinauer; 1996. p. 407514.

35. Hershkovitz MA. Leaf morphology of Cistanthe Spach (Portulacaceae). Ann Missouri Bot Gard. 1991;78:1022-1060. http://www.jstor.org/stable/2399742

36. Hershkovitz MA. Leaf morphology and taxonomic analysis of Cistanthe tweedyi (nee Lewisia tweedyi; Portulacaceae). Syst Bot. 1992;17:220-238. http://www.jstor.org/stable/2419519 
Hershkovitz Montiaceae Phylogeny and Phylogeography

37. Hershkovitz MA, Lewis LB. Deep-level diagnostic value of the rDNA-ITS region. Mol Biol Evol. 1996;13:1276-1295. https://doi.org/10.1093/oxfordjournalsmolbev.a025693

38. Hershkovitz MA, Zimmer EA. Conservation patterns in angiosperm rDNA-ITS2 sequences. Nucleic Acids Res. 1996;24:2857-2867. https://doi.org/10.1007/s10670-017-9888-0

39. Hershkovitz MA, Zimmer EA, Hahn WJ. Ribosomal DNA and angiosperm evolution. In: Hollingsworth PM, Bateman RM, Gornall RJ, editors. Molecular systematics and plant evolution. London: Taylor \& Francis; 1999. p. 268-326.

40. Sullivan J, Swofford DL. Should we use model-based methods for phylogenetic inference when we know that assumptions about among-site rate variation and nucleotide substitution pattern are violated? Syst Biol. 2001;50:723-729. http://www.jstor.org/stable/3070810

41. Garcia N, Meerow AW, Soltis DE, Soltis PS. Testing deep reticulate evolution in Amaryllidaceae tribe Hippeastreae (Asparagales) with ITS and chloroplast sequence data. Syst Bot. 2014;39:75-89. https://doi.org/10.1600/036364414X678099

42. Hershkovitz MA. Leaf morphology of Calandrinia Kunth and Montiopsis Kuntze (Portulacaceae). Ann Missouri Bot Gard. 1993;80:366-396. http://www.jstor.org/stable/2399742

43. Kelley WA. Pollen morphology and relationships in the genus Calandrinia H. B. K. Master's thesis, California State University, Northridge (CA); 1973.

44. Ford\#\#\#\#\#[-Werntz] DI. Systematics and evolution of Montiopsis subgenus Montiopsis (Portulacaceae). PhD dissertation, Washington University, St Louis; 1992.

45. Hinton WF. Systematics of the Calyptridium umbellatum complex (Portulacaceae). Brittonia 1975;27:197-208. https://doi.org/10.2307/2805891

46. Reiche K. Zur systematik der chilenischen Arten der Gattung Calandrinia. Ber Deutsch Bot Ges. 1897;15:493-503. https://www.biodiversity.org/page/5001588

47. Reiche K. Estudios críticos sobre la flora de Chile. Anales Univ Chile 1898;100:327-371. \#\#\#\#[Reiche, C. Portulacaceae. In: Reiche C, editor. Flora de Chile, vol. 2. Santiago: Cervantes; 1898. p. 327-371.] https://www.biodiversity.org/item/27136

48. Hershkovitz MA. Nomenclatural changes in Portulacaceae. Phytologia 1990;68:267-270. https://doi.org/10.5962/bhl.part.5799

49. Hershkovitz MA. Taxonomic notes on Cistanthe, Calandrinia, and Talinum. Phytologia 1991;70:209-225. https://www.biodiversity.org/page/12983019

50. Guilliams CM. Phylogenetic reconstruction, character evolution, and conservation in the genus Calyptridium (Montiaceae). Master's thesis, San Diego State University; 2009. http://www.sci.sdsu.edu/plants/lab/Guilliams2009-ThesisCalyptridium-Montiac-r.pdf 
Hershkovitz Montiaceae Phylogeny and Phylogeography

51. Ogburn RM, Edwards EJ. Repeated origin of three-dimensional leaf venation releases constraints on the evolution of succulence in plants. Curr Biol. 2013;23:722-726.

https://doi.org/10.1016/j.cub.2013.03.029

52. Mathew B. The genus Lewisia. Portland (OR): Timber Press; 1989.

53. Soltis DE, Albert VA. Leebens-Mack J, Bell CD, Paterson AH, Zheng C, Sankoff D, dePamphilis CW, Wall PK, Soltis PS. Polyploidy and angiosperm diversification. Amer J. Bot 2009;96:336-348. https://doi.org/10.3732/ajb.0800079

54. Hershkovitz MA, Arroyo MTK, Bell C, Hinojosa LF. Phylogeny of Chaetanthera (Asteraceae: Mutisieae) reveals both ancient and recent origins of the high elevation lineages. Mol Phylogen Evol. 2006;41:594-605. https://doi.org/10.1016/j.ympev.2006.05.003

55. Davidson R. Lewisias. Portland (OR): Timber Press; 2000.

56. Hershkovitz MA. Phylogenetic studies in Centrospermae: a brief appraisal. Taxon 1989;38:602-608. http://www.jstor.org/stable/2419519

57. Rodman JE, Oliver MK, Nakamura RR, McClammer Jr JU, Bledsoe AH. A taxonomic analysis and revised classification of Centrospermae. Syst Bot. 1984;9:297-323.

http://www.jstor.org/stable/2418610

58. Rodman JE..Cladistic and phenetic studies. In: Behnke HD, Mabry TJ, editors. Caryophyllales, evolution and systematics. Berlin: Springer; 1994. p. 279-301.

59. Giannasi DE, Zurawski G, Learn G, Clegg M. Evolutionary relationships of the Caryophyllidae based on comparative $r b c \mathrm{~L}$ sequences. Syst Bot. 1992;17:1-15. http://www.jstor.org/stable/2419059

60. Rettig JH, Wilson HD, Manhart JR. Phylogeny of the Caryophyllales: gene sequence data. Taxon 1992;41:201-209. http://www.jstor.org/stable/1222329

61. Downie SR, Palmer JD. A chloroplast DNA phylogeny of the Caryophyllales based on structural and inverted repeat restriction site variation. Syst Bot. 1994;19:236-252. http://www.jstor.org/stable/2419599

62. Manhart JR, Rettig JH. Gene sequence data. In: Behnke HD, Mabry TJ, editors. Caryophyllales, evolution and systematics. Berlin: Springer; 1994. p. 235-246.

63. Cuénod, P, Savolainen V, Chatrou LM, Powell M, Grayer RJ, Chase MW. Molecular phylogenetics of Caryophyllales based on nuclear 18S rDNA and plastid rbcL, atpB and matK DNA sequences. Amer J Bot. 2002;89:132-144. https://doi.org/10.3732/ajb.89.1.132

64. Kew Scientist. Cacti present a prickly problem. Kew Sci. 2001;20:2.

65. Brummitt RK. How to chop up a tree. Taxon 2002;51:31-41.Cuenod

66. Gorelick R. Fishing for phylogenetic foibles. Ideas Ecol Evol. 2014;7:8-10. http://citeseerx.ist.psu.edu/viewdoc/download?doi=10.1.1.680.307\&rep=rep1\&type=pdf 
Hershkovitz Montiaceae Phylogeny and Phylogeography

67. Humphries CJ, Parenti LR. Cladistic biogeography: interpreting patterns of plant and animal distributions. Oxford: Clarendon; 1986.

68. Humphries CJ, Parenti LR. Cladistic biogeography: interpreting patterns of plant and animal distributions. 2nd. ed. Oxford: Clarendon; 1999.

69. Raven PH, Axelrod DI. Angiosperm biogeography and past continental movements. Ann Missouri Bot Gard. 1974;61:539-673. http://www.jstor.org/stable/2395021

70. Moreira Muñoz A. Plant geography of Chile: an essay on postmodern biogeography. Berlin: Springer; 2011. https://www.researchgate.net/profile/Andres_Moreira2/publication/240997817_The_Extravagant_Ph ysical_Geography_of_Chile/links/0deec534e6f3ba23d6000000/The-Extravagant-PhysicalGeography-of-Chile.pdf

71. Donoghue MJ. Bipolar biogeography. Proc Nat Acad Sci USA. 2011;108:6341-6342. https://doi.org/10.1073/pnas.1103801108

72. Moore MJ, Tye A, Jansen RK. Patterns of long-distance dispersal in Tiquilia subg Tiquilia (Boraginaceae): implications for the origins of amphitropical disjuncts and Galapagos Islands endemics. Amer J Bot. 2006;93:1163-1177. https://doi.org/10.1016/j.ympev.2006.01.020

73. Heads M. Inferring biogeographic history from molecular phylogenies. Biol J Linn Soc. 2009;98:757-774. https://doi.org/10.1111/j.1095-8312.2009.01320.x

74. Heads M. Biogeography and Evolution in New Zealand. Boca Raton FL: CRC; 2016.

75. Heads M. Biogeography of Australasia: A Molecular Analysis. Cambridge UK \& New York NY: Cambridge University; 2014.

76. Gibbons AD, Whittaker JM, Müller RD. The breakup of East Gondwana: assimilating constraints from Cretaceous ocean basins around India into a best-fit tectonic model. J Geophys Res Solid Earth 2013;118:808-822. https://doi.org/10.1002/jgrb.50079

77. Elvebakk A, Flores AR, Watson JM. Revisions in the South American Calandrinia caespitosa complex (Montiaceae). Phytotaxa 2015;203:91-23.

https://www.researchgate.net/profile/Arve_Elvebakk/publication/281398515_Revisions in the Sout h_American_Calandrinia_caespitosa_complex_Montiaceae/links/56715b2f08ae2b1f87aee889/Revis ions-in-the-South-American-Calandrinia-caespitosa-complex-Montiaceae.pdf

78. O'Quinn RL. Phylogeny, biogeography and evolution of perennation structures in Montieae (Portulacaceae). PhD dissertation, Washington State Univ., Pullman (WA); 2005. https://research.wsulibs.wsu.edu/xmlui/bitstream/handle/2376/297/r_oquinn_020905.pdf?sequence= 1 
Hershkovitz Montiaceae Phylogeny and Phylogeography

79. Livermore R., Hillenbrand C-D, Meredith M, Eagles G. Drake passage and Cenozoic climate: an open and shut case? Geochem Geophys Geosyst. 2007;8:Q01005. https://doi.org/10.1029/2005GC001224.

80. Francis JE, Marenssi S, Levy R, Hambrey M, Thorn VT, Mohr B, Brinkhuis H, Warnaar J, Zachos J, Bohaty S, DeConto R. From greenhouse to icehouse - the Eocene/Oligocene in Antarctica. In: Florindo F, Siegert M, editors. Developments in Earth \& Environmental Sciences. Vol. 8. Oxford: Elsevier; 2009 p. 311-372. https://doi.org/10.1016/S1571-9197(08)00008-6

81. Nyffeler R. The closest relatives of cacti: insights from phylogenetic analyses of chloroplast and mitochondrial sequences with special emphasis on relationships in the tribe Anacampseroteae. Amer J Bot. 2007;94:89-101. https://doi.org/10.3732/ajb.94.1.89

82. Geesink R. An account of the genus Portulaca in Indo-Australia and the Pacific. Blumea 1969;17:275-301. http://repository.naturalis.nl/document/565992

83. Ocampo G, Columbus JT. Molecular phylogenetics, historical biogeography, and chromosome evolution of Portulaca (Portulacaceae). Mol Phylogen Evol. 2012;63:97-112. https://doi.org/10.1016/j.ympev.2011.12.017

84. Matthen M, Ariew A. Selection and causation. Philos Sci. 2009;76:201-224. https://doi.org/10.1086/648102

85. Carlquist S. The biota of long-distance dispersal. V. Plant dispersal to Pacific Islands. Bull Torrey Bot Club 1967;94:129-162.

86. Pole M. The New Zealand flora-entirely long distance dispersal? J Biogeogr. 1994;21:625-635. http://www.jstor.org/stable/2846036

87. Tay ML. Evolution of Australian Plantago (Plantaginaceae). Master's thesis, Victoria University, Wellington, NZ; 2008. http://researcharchive.vuw.ac.nz/xmlui/bitstream/handle/10063/357/thesis.pdf? sequence=1

88. Givnish TJ, Renner SS. Tropical intercontinental disjunctions: Gondwana breakup, immigration from the boreotropics, and transoceanic dispersal. Int J P1 Sci 2004;165 Suppl 4:51-56. https://doi.org/10.1086/424022

89. Edwards EJ, Donoghue MJ. Is it easy to move and easy to evolve? Evolutionary accessibility and adaptation. J Exper Bot. 2013;64:4047-4052. https://doi.org/10.1093/jxb/ert220

90. Nathan R. Long-distance dispersal of plants. Science 2006;313:786-788. https://doi.org/10.1126/science.1124975

91. Nathan R, Schurr FM, Spiegel O, Steinitz O, Trakhtenbrot A, Tsoar A. Mechanisms of long-distance seed dispersal. TREE 2008;23:638-647. https://doi.org/10.1016/j.tree.2008.08.003 
Hershkovitz Montiaceae Phylogeny and Phylogeography

1 92. Crisp MD, Trewick SA, Cook LG. Hypothesis testing in biogeography. TREE 2011;26:66-72.

2

3

4

5

6

7 https://doi.org/10.1016/j.tree.2010.11.005

93. Gillespie RG, Baldwin BG, Waters JM, Fraser CI, Nikula R, Roderick GK. Long-distance dispersal: a framework for hypothesis testing. TREE 2012;27:47-56. https://doi.org/10.1016/j.tree.2011.08.009

94. Wenzel JW, Carpenter JM. Comparing methods: adaptive traits and tests of adaptation. In: Eggleton P, Vane-Wright RI, editors. Phylogenetics and Ecology. London: Academic Press; 1994. p. 79-101.

95. Delport PT. The tick, the gods, and the contract. Phronimon 2012;13:39-54. https://journals.co.za/deliver/fulltext/phron/13/2/phron_v13 n2 a4.pdf?itemId=/content/phron/13/2/ $\underline{\text { EJC128691\&mimeType }=\text { pdf\&containerItemId }=\text { content } / \text { journal/phron }}$

96. Moore BR, Donoghue MJ. Correlates of diversification in the plant clade Dipsacales: geographic movement and evolutionary innovations. Amer Nat. 2007;170. Suppl S28-S55.

https://doi.org/10.1086/519460 